\title{
PUBliCIDAD, PRÁCTICAS COMERCIALES AGRESIVAS, Y FICHEROS DE EXCLUSIÓN VOLUNTARIA O LISTAS ROBINSON EN EL ÁMBITO DIGITAL: UNA SUGERENTE VISIÓN DESDE EL DERECHO ESPAŃOL*
}

\author{
DAVID LÓPEZ JIMÉNEZ**
}

RESUMEN: La actividad publicitaria se ha desarrollado desde tiempo inmemorial. Aunque representa un fenómeno con ciertos aspectos positivos, debe considerarse que, en ocasiones, sobre todo haciendo uso de las nuevas tecnologías, pueden remitirse comunicaciones comerciales electrónicas sin contar con el previo consentimiento del destinatario de las mismas. Para, precisamente, poner freno a estas últimas, en base a la autorregulación del sector, se han creado los ficheros de exclusión voluntaria o listas Robinson que desempeñan una sugerente labor. En base a los mismos, los consumidores y/o usuarios pueden manifestar su oposición expresa a la remisión de comunicaciones comerciales, a través de ciertos canales, respecto a bienes y servicios de determinadas empresas. En el presente artículo tendremos como objetivo analizar, desde la óptica del Derecho espańol (sin perjuicio de ciertos apuntes al Derecho comparado), determinadas cuestiones que se suscitan como consecuencia de las violaciones de la privacidad de los titulares de los datos tratados. Así, entre otros aspectos, examinaremos la remisión de comunicaciones comerciales electrónicas no deseadas, el acoso como práctica comercial desleal y los ficheros de exclusión voluntaria. Una de las conclusiones que se derivarán es la sugerente labor complementaria $-y$, por tanto, no excluyente de la ley- que los instrumentos de autorregulación -como las listas Robinsonrealizan respecto a la normativa legal.

\footnotetext{
* $\quad$ Este trabajo forma parte del Proyecto de investigación FONDECYT $\mathrm{N}^{\circ} 11130188$, del que el autor es Investigador Principal.

Fecha de recepción: 22 de agosto de 2013.

Fecha de aceptación: 4 de diciembre de 2013.

** Doctor (con mención especial europea) por la Universidad de Sevilla (Espańa). También es Doctor por la Universidad Rey Juan Carlos de Madrid (España). Ambas tesis fueron calificadas con sobresaliente cum laude por unanimidad del tribunal calificador (máximo posible). Es Premio Extraordinario de Doctorado (mejor tesis doctoral en el ámbito de las Ciencias Jurídicas). Ha realizado diferentes postgrados universitarios en varias universidades españolas -tres maestrías y tres cursos de experto universitario-. Posesión de dos Diplomas de Estudios Avanzados con nota media de sobresaliente (equivalente a Máster). Es Profesor Titular de la Universidad Autónoma de Chile. Correo electrónico: dlopezjimenez@gmail. com; david.lopez@uautonoma.cl
} 
Palabras ClaVE: Consentimiento - ficheros - lista Robinson - publicidad - privacidad.

\title{
ADVERTISING, AGGRESSIVE COMMERCIAL PRACTICES, AND THE VOLUNTARY EXCLUSION FILES OR ROBINSON LISTS IN THE DIGITAL ENVIRONMENT: A SUGGESTIVE POINT OF VIEW FROM SPANISH LAW
}

\begin{abstract}
The advertising activity has been developing since a long time ago. Although it represents a phenomenon with certain positive aspects, it has to be considered that, sometimes, and especially making use of new technologies, electronic commercial communications can be sent without having the receivers' previous consent. In order to stop this, and according to the sector self-regulation, voluntary exclusion files or Robinson lists have been created, which have a suggestive task. Based on these, consumers and/or users can express their specific opposition to commercial communications sendings, through particular channels, related to the goods and services of certain companies. In this paper we aim to analyze, from the perspective of Spanish law (independently to certain notes to Comparative law), certain issues that arise as a result of violations to the user's privacy of the data processed. Thus, among other things, we will examine the mailing of unwanted commercial electronic communications, harassment as an unfair business practice and the voluntary exclusion files. One conclusion that will be derived is the suggestive complementary work -and, therefore, not exclusive of the law- that self-regulatory instruments -such as the Robinson lists- perform regarding to legal rules.
\end{abstract}

KEY WORDS: Consent - files - Robinson lists - advertising - privacy.

Sumario: Introducción. 2) La publicidad en la actual era tecnológica. (2.1) Delimitación conceptual. (2.2) El recurso a técnicas comerciales eventualmente agresivas: preponderancia de la persuasión sobre la información. 3. La remisión de comunicaciones comerciales electrónicas no solicitadas. (3.1) Concepto. (3.2) El sistema de inclusión voluntaria vs. exclusión voluntaria (3.2.1.) La regulación en el plano comunitario. (3.2.2.) La regulación en el ámbito español. (3.3) El acoso como práctica comercial desleal en la materia. 4. Los ficheros de exclusión voluntaria o listas Robinson. (4.1) Delimitación conceptual. (4.2) A propósito de su posible consideración como manifestación de la autorregulación del sector. Conclusiones. Bibliografia. 


\section{1) INTRODUCCIÓN}

La publicidad, desde antaño, se ha erigido en una herramienta esencial y consustancial a la economía. No en vano, como planteamos, desde tiempo inmemorial, fabricantes y comerciantes han recurrido a la misma como instrumento apto para fomentar la demanda de los potenciales destinatarios de los bienes y/o servicios que ofertaban. Ahora bien, los primeros ejemplos de esta forma de entender la publicidad pueden encontrarse en el desarrollo del capitalismo. En la actualidad, la publicidad constituye una actividad de extraordinaria relevancia. Puede, en cierta medida, afirmarse que, además de un vehículo de comunicación, es un mecanismo dinamizador de la economía.

El objetivo inmediato de la publicidad no es modificar los valores o los comportamientos sociales, sino provocar actitudes y conductas de consumo. Sin embargo, es indudable que es un dispositivo conformador de los valores sociales, favoreciendo aquellos que provocan un aumento de los hábitos consumistas. En este sentido, podría manifestarse que el deseo de persuadir ha estado, de una u otra forma, presente desde siempre en la Humanidad. Lo único que, en cierta medida, ha ido cambiando, en cada época, son los medios a nuestro alcance.

Toda empresa que, en la actualidad, pretenda perdurar en el mercado competitivo global debe incorporar las nuevas tecnologías en su actividad cotidiana, para estar permanentemente adecuada a las tendencias de venta, a través de los nuevos medios tecnológicos, y poder diseñar estrategias de marketing electrónico. La necesidad de las empresas de mantener los clientes y de estrechar relaciones con los mismos, determina que aquellas busquen formas de llegar directamente al consumidor individual, personalizando la oferta, constituyendo, de esta manera, novedosos tipos de venta que permiten que las empresas establezcan relaciones continuadas y directas con el mismo, esté donde esté.

En línea con cuanto venimos poniendo de manifiesto, cabe indicar que uno de los aspectos más interesantes que los contratos celebrados con consumidores presentan es el relativo a su período precontractual ${ }^{1}$, es decir, todas aquellas actividades que se desarrollan entre las partes, antes de

\footnotetext{
Vinculado con ello, véanse los interesantes trabajos realizados por DE la Maza Gazmuri, Iñigo (2010). "El suministro de información como técnica de protección de los consumidores: los deberes precontractuales de información". Revista de Derecho de la Universidad Católica del Norte, N² 2, pp. 21-52; De la Maza Gazmuri, Iñigo (2010). Los límites del deber precontractual de información. Navarra: Civitas y Thomson Reuters; De la Maza Gazmuri, Ińigo (2010). "Tipicidad y atipicidad de los deberes precontractuales de información". Revista de Derecho de la Pontificia Universidad Católica de Valparaíso, N³4, pp. 75-99; DE LA Maza Gazmuri, Iñigo (2011). "La distribución del riesgo y la buena fe. A propósito del error, el dolo y los deberes precontractuales de información”. Revista de Derecho de la Pontificia Universidad Católica de Valparaíso, $\mathrm{N}^{\circ} 37$, pp. 115-135.
} 
que otorgue el consentimiento, para la perfección del contrato. En este instante, es relativamente habitual que el consumidor y/o usuario tenga conocimiento de las características esenciales del bien y/o servicio que pueden interesarle, del que puede estar informado en virtud de la publicidad recibida ${ }^{2}$-tanto a través de canales tradicionales como virtuales-.

El impacto que las nuevas tecnologías ha supuesto en la publicidad es realmente significativo. Así, entre otros aspectos, ha permitido una elevada personalización del mensaje, con lo que se aumenta sensiblemente la eficacia de la comunicación publicitaria. Para, precisamente, operar tal individualización, se emplean diversas técnicas -entre otras, cookies ${ }^{3}$, spyware ${ }^{4}$ y web bugs $s^{5}$ que, en ocasiones, pueden no haber sido conocidas ni, mucho menos, consentidas, lo que, naturalmente, merece un juicio de reproche.

Estos últimos instrumentos tecnológicos, entre otros aspectos, recaban datos personales de sus legítimos titulares a efectos de remitirles comunicaciones electrónicas comerciales sobre bienes y/o servicios que previsiblemente serán de su interés, ya que estarán altamente personalizados en función a la persona de que se trate. Para que estos mensajes resulten legítimos, en el caso español, el receptor ha tenido que otorgar, con carácter previo, su consentimiento. En el supuesto contrario, estamos ante lo que frecuentemente se denomina spam, práctica, todo hay que decirlo, invasiva de la privacidad. Esta última ha sido uno de los mayores inconvenientes en el uso de las comunicaciones electrónicas ${ }^{6}$.

2 Sobre este particular, sugerimos la lectura de Guillén Catalán, Raquel (2010). El régimen juridico de la oferta contractual dirigida a consumidores. Madrid: Colegio de Registradores de la Propiedad y Mercantiles de España.

3 Las cookies son pequeños ficheros de texto que algunos servidores Web piden a nuestro navegador. Escriben en nuestro disco duro información sobre lo que hemos estado haciendo en sus páginas Web. La cookie está formada por el nombre del usuario, configurado en el navegador, seguido del símbolo arroba (@), y el nombre del servidor que envía la cookie, más la extensión "txt" que la identifica como fichero de texto. En relación a las mismas, para ampliar tal información, véase el trabajo realizado por De la Maza Gazmuri, I. (2002). "Privacidad y comercio electrónico". En De la Maza Gazmuri, I. (Coord.): Derecho y Tecnologías de la Información. Santiago: Escuela de Derecho Universidad Diego Portales, pp. 265-279.

4 Los spyware son programas espía que monitorizan el comportamiento de los consumidores $y$, adicionalmente, ocasionan fallos en el rendimiento y estabilidad de los ordenadores.

5 Tienen que ver con actuaciones inconscientes cuya repercusión podría pasar desapercibidas. En efecto, para registrar y rastrear la apertura de un documento -por ejemplo, un correo electrónico- por Internet, se incluye en el mismo una imagen vinculada a un servidor distinto al que aloja la página Web que estamos visitando. Son gráficos, de un píxel por un píxel, que instalan un programa en el disco duro con la finalidad de leer todas las cookies incluidas en el mismo.

6 Respecto a los riesgos que las nuevas tecnologías pueden conllevar, en cuanto a la tutela de los datos personales, véase, entre otros, los sugerentes estudios de BANDA Vergara, Alfonso (2000). "Manejo de datos personales. Un límite al derecho a la vida privada". Revista de Derecho (Valdivia), No 11, pp. 55-70; Cerdá Silva, Alberto (2006). "Mecanismos 
Para poner freno a esta última práctica comercial no deseada, se han elaborado los denominados ficheros de exclusión voluntaria o Listas Robinson. Estos últimos constituyen una sugerente manifestación de la autodisciplina del sector, fomentada, dicho sea de paso, por el legislador estatal -en el caso concreto de España a impulsos de su homónimo comunitario $^{7}$-. En base a los mismos, los consumidores y/o usuarios pueden manifestar, haciendo uso del principio de la autonomía privada, su oposición a la remisión de comunicaciones comerciales, a través de ciertos canales, respecto a bienes y servicios de determinadas empresas. La inscripción en esta modalidad de listas podrá realizarse tanto antes como después de haber recibido mensajes comerciales no solicitados, sin perjuicio de que lo más habitual será este último supuesto. En el presente artículo tomaremos como base el examen de la legislación española, a propósito del particular, sin perjuicio de que, cuando proceda, efectuaremos las remisiones oportunas en el ámbito del Derecho comparado. Entendemos que la regulación de esta materia en el caso del Derecho español representa un paradigma que debe ser tenido en consideración para la tutela de este tipo de datos en otros sistemas jurídicos.

En el presente artículo analizaremos ciertas cuestiones que, en este sentido, se suscitan como consecuencia de las violaciones de la privacidad de los titulares de los datos tratados. Así, entre otros aspectos, estudiaremos, con carácter general, la remisión de comunicaciones comerciales electrónicas no deseadas -nos ocuparemos, además de su concepto, de los sistemas de inclusión voluntaria vs. exclusión voluntaria-, el acoso como práctica comercial desleal y los ficheros de exclusión voluntaria. Todo ello sin perjuicio del examen que, a continuación, efectuaremos de la promoción comercial en el ámbito digital.

\section{2) LA PUBLICIDAD EN LA ACTUAL ERA TECNOLÓGICA}

Una de las manifestaciones más significativas que las Tecnologías de la Información y de la Comunicación han supuesto, a nivel empresarial, se observa en la publicidad interactiva, dentro de la que ocupa una posición de excelencia la que se desarrolla en Internet ${ }^{8}$. Puede, a tal efecto, afirmarse que el sistema de promoción tradicional ha perdido valor en be-

de control en la protección de datos en Europa”. Ius et Praxis, N ${ }^{\circ} 36$, pp. 221-251; Cerdá Silva, Alberto (2011). "El "nivel adecuado de protección” para las transferencias internacionales de datos personales desde la Unión Europea”. Revista de Derecho de la Pontificia Universidad Católica de Valparaiso, N³6, pp. 327-356.

$7 \quad$ Tales listas se enuncian, entre otros documentos comunitarios, en el considerando 31 y en el art. 7.2 de la Directiva europea de comercio electrónico.

8 Sobre este extremo, véase ampliamente López Jiménez, David (2013). La publicidad en Internet. Regulación y autorregulación. Navarra: Thomson Reuters. 
neficio del virtual. A continuación, aludiremos, por un lado, a la delimitación conceptual que, desde la perspectiva del Derecho español, merece la actividad promocional desarrollada en la Red y, por otro, a la primacía de la persuasión sobre la información en todo este orden de cuestiones.

\section{1) DELIMITACIÓN CONCEPTUAL}

La remisión de comunicaciones comerciales a través de medios electrónicos debe reputarse publicidad ${ }^{9}$. Es visible, por consiguiente, el desplazamiento del término "publicidad" por el de "comunicación comercial"10, pero dotando a este de un significado muy próximo al tradicional de publicidad $^{11}$. Podría, en este sentido, considerarse que el recurso al término "comunicación comercial" obedece al deseo del legislador de ensanchar el concepto de referencia, propiciando, de esta manera, la regulación y el control de nuevos fenómenos promocionales que podían encontrar en el nuevo escenario de la publicidad interactiva un ámbito de desarrollo particularmente favorable ${ }^{12}$. En todo caso, aunque el término publicidad ${ }^{13}$ se menciona en el apartado 2.i) del anexo de la Ley espańola 34/2002, de 11 de julio, de

9 En igual sentido, Espinosa Calabuig, Rosario (2001). La publicidad transfronteriza. Valencia: Tirant lo Blanch, pp. 98-100; Fernando Magarzo, María del Rosario (2001). "Concepto de publicidad y publicidad engañosa en Internet". Revista de la Contratación Electrónica, N²1, pp. 28-29; Tato Plaza, Anxo (2001). "Aspectos jurídicos de la publicidad y de las comunicaciones comerciales en Internet”. En Gómez Segade, José Antonio (Dir.): Comercio Electrónico en Internet. Madrid: Marcial Pons, pp. 191-196; Illescas Ortiz, Rafael (2003). "Comunicaciones comerciales y oferta contractual electrónicas: la propuesta de contrato entre la prohibición y las incertezas". Revista de la Contratación Electrónica, $\mathrm{N}^{\circ} 40$, pp. 7-11; Rivero González, María Dolores (2003). "Régimen jurídico de la publicidad en Internet y las comunicaciones comerciales no solicitadas por correo electrónico". Revista de Derecho Mercantil, No 250, pp. 1591-1593; Tato Plaza, Anxo (2004). "La publicidad en Internet". En González Delgado, José Ángel (Coord.): Responsa iurisperitorum digesta. Salamanca: Ediciones de la Universidad de Salamanca, p. 96; Vega VegA, José Antonio (2005). Contratos electrónicos y protección de los consumidores. Madrid: Reus, pp. 169-172; Arias Pou, María (2006). Manual Práctico de Comercio Electrónico. Madrid: La Ley, pp. 241244; Sánchez del Castillo, Vilma (2007). La publicidad en Internet. Régimen Jurídico de las comunicaciones electrónicas. Madrid: La Ley, pp. 87-90.

10 Illescas Ortiz (2003) 7-11, se manifiesta partidario de que el término comunicación comercial en la LSSI-CE sea interpretado en el sentido de mensaje publicitario en soporte electrónico.

11 Bodewig, Theo (2000). "Electronischer Geschäftsverkehr und Unlauterer Wettbewerb”. GRUR Int., No 27, p. 476, considera que se trata de una aportación de dudosa eficacia.

12 Álvarez Rubio, Julio (2008). "Hacia un nuevo concepto legal de comunicación comercial". En Tomillo Urbina, Jorge Luis (Dir.) y Álvarez Rubio, Julio (Coord.): El futuro de la protección jurídica de los consumidores. Actas del I Congreso Euroamericano de Protección Juridica de los Consumidores. Navarra: Thomsom Civitas y Cátedra Euroamericana de Protección Jurídica de los Consumidores, p. 119.

13 Cierto sector de la doctrina se posiciona en contra de que el legislador español defina la publicidad. Así, por ejemplo, Desantes Guanter, José María (1980). "El marco jurídico de la publicidad en el contexto de la información". En Primeras Jornadas de Derecho de la Publicidad. Madrid: Instituto Nacional de Publicidad, p. 32; PÉrez, Alberto (1980). "El 
Servicios de la Sociedad de la Información y Comercio Electrónico ${ }^{14}$ (en adelante LSSI-CE), el que se define es el de comunicación comercial ${ }^{15}$-del mismo modo que en la Directiva europea de comercio electrónico-.

En este sentido, de acuerdo con el anexo f) de la LSSI-CE, podemos definir comunicación comercial electrónica como "toda forma de comunicación ${ }^{16}$ dirigida a la promoción, directa o indirecta, de la imagen o de los bienes o servicios de una empresa, organización o persona que realice una actividad comercial, industrial, artesanal o profesional. A efectos de esta Ley, no tendrán la consideración de comunicación comercial los datos que permitan acceder directamente a la actividad de una persona, empresa u organización, tales como el nombre de dominio o la dirección de correo electrónico, ni las comunicaciones relativas a los bienes, los servicios o la imagen que se ofrezca cuando sean elaboradas por un tercero y sin contraprestación económica" 17 . Como puede deducirse, la citada norma contempla una acepción positiva y otra negativa de comunicación comercial.

En cuanto a la primera -de carácter positivo-, cabe señalar que incide en la labor de promoción que el anunciante opera, respecto a ciertos productos o servicios, en el ejercicio de su actividad comercial virtual, lo que supone una comunicación entre el anunciante y el receptor de la publicidad -destinatario que podrá ser individual o colectivo, dado que la definición no exige que el mensaje necesariamente se dirija a una pluralidad de personas-. Ha de advertirse que tales actuaciones deben respetar no solo las previsiones establecidas en la LSSI-CE, sino también las normas imperantes en materia publicitaria y comercial ${ }^{18}$. Interesa poner de

concepto jurídico de la publicidad". En Primeras Jornadas de Derecho de la Publicidad. Madrid: Instituto Nacional de Publicidad, pp. 89 y 90.

14 BOE núm. 166 de 12 de julio de 2002.

15 Dicho concepto de comunicación comercial es objeto de reiteración, en lo sustancial, en el art. 2.a) de la Propuesta de Reglamento, de 4 de octubre de 2001, relativo a las promociones de ventas en el mercado interior.

16 El recurso a la expresión "toda forma de comunicación" constituye un claro acierto. En efecto, las nuevas técnicas de comunicación -que, en el espacio digital, avanzan a un ritmo imparable-, dan lugar a nuevos formatos publicitarios. En este sentido, también TeJEDOR Muñoz, Lourdes (2010). "Consideraciones en torno a la publicidad confusionista a la luz de Ley 29/2009, de 30 de diciembre, por la que se modifica el régimen legal de la competencia desleal y de la publicidad para la mejora de la protección de los consumidores y usuarios". Revista Crítica de Derecho Inmobiliario, N 721, p. 2435; Tejedor Muñoz, Lourdes (2010). "La publicidad engañosa, comparativa y prácticas comerciales desleales". En Díaz-Ambrona Bajardí, María Dolores (Dir.): Derecho Civil de la Unión Europea, 4a edición. Madrid: Colex, p. 282.

17 La primera norma española que delimitó este tipo de publicidad presentaba carácter autonómico. Se trata del art. 1.3.e) de la Ley 5/1997, de 8 de julio, por la que se regula la publicidad dinámica en las Islas Baleares (BOE núm. 192 de 12 de agosto de 1997), que la definió como aquella actividad consistente en "el envío de mensajes publicitarios mediante comunicación telefónica, por fax o a través del llamado correo electrónico".

18 Cabe, entre otras muchas, destacar la Ley espańola 34/1988, de 11 de noviembre, General de Publicidad (BOE núm. 274 de 15 de noviembre de 1988); Ley española 3/1991, de 10 
manifiesto que el precepto que analizamos, trae causa del art. 2.f) de la Directiva comunitaria de comercio electrónico ${ }^{19}$ que, a su vez, coincide, de manera sustancial, con la operada por el Libro Verde de la Comisión Europea, de 23 de mayo de 1996, sobre las comunicaciones comerciales en el mercado interior.

Estamos, como puede verse, ante una delimitación bastante amplia, dado que incluye toda modalidad de publicidad virtual. Además, tal inclusión debe considerarse con independencia del formato del mensaje comercial (audiovisual, gráfico y/o sonoro). De igual modo, en la definición que analizamos, tendrían cabida tanto las actividades publicitarias electrónicas que se refieren a un colectivo indeterminado-como, por ejemplo, es el banner ${ }^{20}$ - como las actividades de marketing directo ${ }^{21}$ que se dirigen a destinatarios concretos y determinados -así un correo electrónico ${ }^{22}$-. En todo caso, la finalidad del mensaje digital comercial debe ser la promoción de bienes y/o servicios o la imagen de la empresa.

Tal presupuesto determinará que excluyamos del carácter de comunicación comercial, al menos, tres modalidades de mensajes. En primer lugar, los mensajes difundidos en Internet con una finalidad puramente informativa -que no han de confundirse, en modo alguno, con la publi-

de enero, de Competencia Desleal (BOE núm. 10, de 11 de enero de 1991); Ley española 7/1996, de 15 de enero, de Ordenación del Comercio Minorista (BOE núm. 15 de 17 de enero de 1996) y; Real Decreto Legislativo español 1/2007, de 16 de noviembre, por el que se aprueba el Texto Refundido de la Ley General para Defensa de los Consumidores y Usuarios y otras Leyes complementarias (BOE núm. 287 de 30 de noviembre de 2007).

19 Diario Oficial ${ }^{\circ}$ L 178 de 17 de julio de 2000.

20 Suelen ser una imagen gráfica que incluye texto cuya pulsación activará un enlace que conducirá al usuario al sitio Web del anunciante. El banner se introdujo, por primera vez, en el sitio Web de la revista Hot Wired que, en octubre de 1994, se difundió en la Red. Así, Kes, Yusuf (2011). "Current approaches in e-advertisement". International Journal of Business and Social Science, Vol. 2, N²1, p. 125.

21 El marketing directo representa una de las actividades de comunicación de la empresa que mayor crecimiento ha protagonizado en los últimos ańos. En este sentido, LeE, Monle (2004). "Attitudes toward direct marketing, privacy, environment and trust: Taiwan vs. U.S.". International Journal of Consumer Marketing, Vol. 14, $\mathrm{N}^{\circ}$ 1, pp. 1-18; Dolnicar, Sara y JoRDAAN, Yolanda (2007). "A market oriented approach to responsibly managing information privacy concerns in direct marketing". Journal of Advertising, Vol. 36, $\mathrm{N}^{\circ} 2$, pp. 123-149.

22 La dirección de correo electrónico se constituye por un elenco, más o menos amplio, de signos o palabras libremente elegidos, generalmente por su titular. La única limitación que, a este respecto, impera es que dicha dirección no sea igual a la que otra persona registró antes. Esta combinación podrá bien tener significado en sí misma bien carecer del mismo. Todo ello habida cuenta del grado de identificación del titular de la cuenta de correo electrónico que proporcione la dirección de que se trate. Así, existirán casos en los que, voluntaria o involuntariamente, la dirección de correo electrónico incorpora información acerca de su titular que lo identifique. En dichos supuestos no existirá duda alguna de que dicha dirección debe de ser reputada como dato de carácter personal. Ahora bien, cuando la dirección de correo electrónico no incluye datos relacionados con la persona titular de la cuenta, no nos encontramos ante un dato de carácter personal. 
cidad encubierta ${ }^{23}$-. En segundo lugar, la publicidad institucional ${ }^{24}$ cuya finalidad sea el fomento de ciertas conductas solidarias - piénsese, por ejemplo, en la donación de órganos-. Y, en tercer y último término, la propaganda política o religiosa que persiga la adhesión de la población a una determinada creencia política o religiosa ${ }^{25}$.

Muy relacionada con la peculiar finalidad de la publicidad en Internet, a la que hemos hecho referencia, se encuentra la exigencia de que la misma se desarrolle en el ejercicio de una actividad comercial, industrial, artesanal o profesional. Tal previsión representa una cuestión significativa, ya que, como es sabido, tanto en el mundo físico como en el virtual, pueden realizarse campañas comerciales que no tengan como finalidad fomentar el consumo de bienes y/o servicios, dado que, a título de ejemplo, pueden promover la moderación en el consumo o ciertos fines de carácter social general ${ }^{26}$.

Ahora bien, a pesar de la amplitud de la definición que estudiamos, existen, además de la restricción negativa -a la que seguidamente nos referiremos-, ciertas limitaciones, pues es preceptivo que los mensajes

23 Estamos ante un caso de publicidad encubierta en un determinado sitio Web cuando los mensajes comerciales de una empresa se presentan bajo la apariencia de una información objetiva -por lo que no son identificables como tales- a cargo de un tercero independiente. Se presenta como información lo que, en realidad, es publicidad. En puridad, podría afirmarse que no se trata de un supuesto engańoso como tal, porque el contenido del mensaje publicitario no lo es, sino que lo es la forma mediante la que se difunde la publicidad -un mensaje publicitario se presenta como un mensaje informativo-, por lo que los destinatarios de la misma pueden llegar a ser más vulnerables.

Algunas normas, dada la enorme amplitud del concepto de publicidad, facilitan la aplicación de su articulado a esta modalidad publicitaria. Así, por ejemplo, el art. 2.f) del Convenio Europeo sobre Televisión Transfronteriza, de 5 de mayo de 1989 (BOE núm. 96 de 22 de abril de 1998), y el art. 3.c) de la Ley espańola 25/1994, de 12 de julio, que incorpora la Directiva de Televisión sin Fronteras (BOE núm. 166, de 13 de julio de 1994). Por otro lado, debemos señalar que la publicidad institucional está regulada por la Ley española 29/2005, de 29 de diciembre, de Publicidad y Comunicación Institucional (BOE núm. 312 de 30 de diciembre de 2005), que establece el marco normativo en el que deben desarrollarse las campañas institucionales promovidas o contratadas por la Administración General del Estado y por las demás entidades integrantes del sector público estatal. También debemos mencionar ciertas normas autonómicas como, entre otras, la Ley española 7/2003, de 20 de marzo, de Publicidad Institucional de la Comunidad Valenciana (BOE núm. 87 de 11 de abril de 2003); Ley espańola 16/2003, de 24 de marzo, de Publicidad Institucional de Aragón (BOE núm. 109 de 7 de mayo de 2003); Ley española 6/2006, de 20 de junio, de Comunicación y Publicidad Institucionales de Asturias (BOE núm. 194 de 15 de agosto de 2006); y la Ley espańola 18/2000, de 29 de diciembre, de Publicidad Institucional de Cataluña (BOE núm. 20 de 23 de enero de 2001).

25 También Patiño Alvés, Beatriz (2002). "Comunicaciones comerciales por vía electrónica". Revista de la Contratación Electrónica, N ${ }^{\circ} 30$, p. 120. Tal criterio resulta, además, confirmado por el art. 13 de la Directiva europea 2002/58 sobre la privacidad y las comunicaciones electrónicas (Diario Oficial n ${ }^{\circ} 201$ de 31 de julio de 2002), ya que las limitaciones que establece al empleo de sistemas de llamada automática, fax o correo electrónico se refieren a su uso con fines de venta directa.

26 Desantes Guanter (1980) 29 y 30; de Miguel Asensio, Pedro Alberto (2005). Régimen jurídico de la publicidad transfronteriza. Madrid: Iustel, p. 36. 
comerciales sean realizados en beneficio de una empresa, organización o persona que efectúe una actividad comercial, industrial, artesanal o profesional. A efectos de la normativa que examinamos, únicamente estos últimos podrán ser reputados anunciantes. Este extremo determina que los mensajes de compraventa entre particulares difundidos en la Red no estén sometidos a la LSSI-CE, sino al Código civil español ${ }^{27}$ (Cc).

Respecto a la acepción de carácter negativo, debe indicarse que alude a aquella actividad en el entorno telemático que, aunque tiene por finalidad tanto la promoción de productos y/o servicios como la potenciación de la propia imagen de la empresa ${ }^{28}$, no merece la consideración de publicidad porque no se realiza en el contexto de una comunicación entre el anunciante y el público destinatario. En este sentido, como pone de relieve la doctrina más autorizada ${ }^{29}$, no deberían, a título de ejemplo, ser reputadas como comunicación comercial los sitios Web en los que se recojan comunicaciones comerciales sobre una determinada empresa, sus productos y/o servicios siempre y cuando la información tenga su origen en un tercero ${ }^{30}$. La normativa legal imperante, como vimos, demanda que dicha información se haya elaborado de manera independiente de la empresa. Tal exigencia parece razonable, pues, en caso contrario, estaríamos ante un supuesto de publicidad encubierta y, por tanto, ilícita. Esta modalidad, como se recordará, acontecería cuando el mensaje publicitario no se presentase como tal, sino con un carácter informativo ${ }^{31}$.

En todo caso, la norma que comentamos, excluye de la consideración de comunicaciones comerciales electrónicas los nombres de dominio ${ }^{32}$.

27 Publicado en La Gaceta de 25 de julio de 1889.

28 Ahora bien, PATiÑo Alvés, Beatriz (2002). "Las comunicaciones comerciales por vía electrónica”. En III Jornadas sobre Derecho del Comercio Electrónico organizadas por la Universidad Carlos III de Madrid. Madrid: Universidad Carlos III, p. 10, dispone que la publicidad corporativa de una empresa, contenida en un sitio Web empresarial, debe ser reputada comunicación comercial.

29 Tato Plaza, Anxo (2001). "Aspectos jurídicos de la publicidad y de las comunicaciones comerciales en Internet”. En Gómez Segade, José Antonio (Dir.) y Fernández-Albor Baltar, Ángel y Tato Plaza, Anxo (Coords.): Comercio electrónico en Internet. Madrid: Marcial Pons, pp. 193.

30 Tal aspecto ha sido valorado negativamente por ciertos autores -como Guillén Catalán, Raquel (2009). Oferta contractual y nuevas tecnologías. Navarra: Thomson Aranzadi, p. 91-, ya que gran parte de tales instrumentos ostentan, junto a la función informativa que le es propia, una marcada función publicitaria. Sobre esta última cuestión, en el sector marcario, véase, entre otros, Arean Lalín, Manuel (1982). "En torno a la función publicitaria de la marca”. Actas de Derecho Industrial, N 8, pp. 57-84; Gondra Romero, José María (1996). "Teoría general de signos de empresa". En Iglesias Prada, Juan Luis (Coord.): Estudios juridicos en homenaje al Profesor Aurelio Menéndez. Madrid: Civitas, pp. 829-868; GHidini, Gustavo (2001). "Funzione distintiva e valore pubblicitario del marchio. Profili e critica di un evolucione”. En Ghidini, Gustavo: Profili evolutivi del Diritto Industriale. Milán: Giuffré, pp. 123 y sigs.

31 Nigra, Amedeo (2001). La publicitá e suoi contratti tipici. Roma: Maggioli, p. 23.

32 Sobre los litigios que, en relación a los mismos, pueden llegar a plantearse véase López Jiménez, David y Castillo Girón, Víctor Manuel (2012). "En torno al conflicto entre 
Estos últimos, que son direcciones que nos permiten acceder al sitio Web de una determinada empresa, organización o persona, desempeñan la función de identificación de la empresa en la Red, así como de los bienes y/o servicios de la misma ${ }^{33}$. Dado que los nombres de dominio, a priori, no promocionan la contratación de los productos ofertados por una empresa no pueden ser considerados comunicación comercial. Ahora bien, cabe referirse a dos situaciones cuya exclusión del concepto de comunicación comercial podría resultar discutible. Por un lado, la presencia del nombre de dominio en un determinado sitio Web contribuye, qué duda cabe, a la promoción de la imagen de la empresa titular del mismo. Tal hipervínculo puede destinarse a información sobre la empresa, pero también a la difusión de comunicaciones comerciales. De esta manera, el nombre de dominio serviría de enlace hacia un espacio puramente publicitario de la Red. Y, por otro, en el patrocinio electrónico, se incluye, en un determinado sitio Web, el nombre de dominio de una empresa, ajena a esa página, a cambio de una contraprestación económica o de otra índole. En todo caso, el legislador español ha optado por excluir los nombres de dominio del concepto de comunicación comercial, aunque determinados supuestos podrían encajar en este último. La razón de tal exclusión probablemente obedece a que la función publicitaria no es propia e inherente a los nombres de dominio, sino que es de carácter indirecto y ocasional.

\section{2) EL RECURSO A TÉCNICAS COMERCIALES EVENTUALMENTE AGRESIVAS: PREPONDERANCIA DE LA PERSUASIÓN SOBRE LA INFORMACIÓN}

La publicidad es un instrumento competitivo ${ }^{34}$, de los más significativos de la sociedad contemporánea ${ }^{35}$, que los operadores económicos utilizan en el tráfico para promover la contratación sobre los bienes y/o

nombres de dominio y otros signos distintivos de las empresas: la política uniforme de solución de controversias". Revista de Estudios Económicos y Empresariales, № 24, pp. 183-217.

33 Deben mencionarse los actos de piratería realizados respecto a los nombres de dominio. La conducta que comentamos consiste en registrar una marca ajena como nombre de dominio para aprovecharse de la buena reputación de aquella. De esta manera, los consumidores y/o usuarios podrían encontrar en la Red nombres de dominio, idénticos a marcas conocidas, que no pertenecen al legítimo titular de esa marca, sino a otro empresario que oferta, desde tal página, publicidad de otros productos y/o servicios. Aunque tales actuaciones podrían, a priori, ser reputadas como un supuesto de publicidad engañosa, lo cierto es que, dado que los nombres de dominio se excluyen del concepto de comunicación comercial, no pueden ser consideradas como tal.

34 Romero Giménez, Manuel (1995). "Publicidad engańosa". En Propiedad Industrial y Competencia Desleal. Madrid: Consejo General del Poder Judicial, pp. 163 y sigs.

35 Alpa, Guido (1986). Diritto privato dei consumi. Bolonia: Il Mulino, p. 123; Suárez Villegas, Juan Carlos y Pérez Chica, María Ángeles (2002). La publicidad al desnudo. Sevilla: Editorial Mad, p. 9. 
servicios que ofertan en el mercado ${ }^{36}$. Es un claro ejemplo de información asimétrica ${ }^{37}$. También ha de repararse en que la publicidad no solo expone los caracteres de los productos y/o servicios, sino que va más allá. En efecto, se configura como un medio que transmite, inculca y exalta determinados valores y pautas de conducta estimados como la base común de la conciencia colectiva ${ }^{38}$.

Tal actividad no solo es información ${ }^{39}$-ni siquiera hoy tiene el máximo protagonismo-, sino que prima la persuasión ${ }^{40}$. Lejos de esperar pasivamente la demanda de sus bienes y/o servicios, los empresarios pretenden anticiparse a la demanda, procurando, de este modo, configurarla y atraerla, lo más posible, hacia sí mismos. Repárese, en todo caso, que la competencia económica de los empresarios, a fecha de hoy, se efectúa en

36 Fernández Novoa, Carlos (1968). "La interpretación jurídica de las expresiones publicitarias". Revista de Derecho Mercantil, N 107, p. 14; Otero Lastres, José Manuel (1977). "La protección de los consumidores contra la publicidad ilícita". Actas de Derecho Industrial y Derecho de Autor, Tomo 4, p. 114; Fernández NovoA, Carlos (1989). "La interpretación jurídica de las expresiones publicitarias. Introducción al estudio de los principios generales de la publicidad". En Estudios de Derecho de la Publicidad (Homenaxe da Facultade de Dereito ó Autor Dr. Carlos Fernández Novoa). Santiago de Compostela: Universidade de Santiago de Compostela, p. 58; Santaella López, Manuel (1989). El nuevo Derecho de la publicidad. Madrid: Civitas, pp. 49 y sigs.; Pardo López, María Magnolia (2009). “Artículo 3”. En LÁzaro SÁnchez, Emilio (Coord.): Comentario a la Ley General de Publicidad. Navarra: Thomson Reuters y Civitas, p. 65.

37 La exigencia de que la información sea veraz permite reprimir las expresiones publicitarias que incluyen alegaciones falsas, suponiendo, de este modo, un abuso de la asimetría en la información entre anunciante y receptor del mensaje comercial. Sobre este particular, Morales Moreno, Antonio Manuel (1988). "Información publicitaria y protección del consumidor (Reflexiones sobre el art. 8 de la LGCU)". En Homenaje a Juan Berchmans Vallet de Goytisolo. Madrid: Consejo General del Notariado, p. 680.

38 Tato Plaza, Anxo (1994). "La explotación publicitaria de los sentimientos y el derecho de la competencia desleal: el caso "Benetton". Derecho de los Negocios, N 44, pp. 13-17.

39 La parcela informativa de la publicidad, aunque sea mínima, debe reconocerse. En este sentido, entre otros, Acosta Estévez, José (1990). Perfiles de la Ley General de Publicidad. Barcelona: Promociones y Publicaciones Universitarias, p. 15; Pino ABAD, Manuel (1991). La disciplina juridica en la actividad publicitaria en la Ley de publicidad de 1988. Madrid: Ministerio de Sanidad y Consumo, p. 41.

40 Ghidini, Gustavo (1968). Introduzione allo studio della pubblicitá comerciale. Milán: Giuffrè, p. 17; Font Galán, Juan Ignacio (1990). "El tratamiento jurídico de la publicidad en la Ley General para la Defensa de los Consumidores y Usuarios”. En Curso sobre el nuevo Derecho del consumidor. Madrid: Ministerio de Sanidad y Consumo, Instituto Nacional de Consumo, pp. 99 y 100; García Guerrero, José Luis (1996). "Publicidad y libertad de expresión en el ordenamiento constitucional español". Derecho Privado y Constitución, $\mathrm{N}^{\circ}$ 10, pp. 117-146; Peinado Gracia, Juan Ignacio (1998). "Comparación y denigración publicitarias de la imagen de empresas indirectamente aludidas (reflexiones con ocasión de la sentencia del Tribunal Supremo de 24 de febrero de 1997)". Revista de Derecho Mercantil, $\mathrm{N}^{\circ}$ 230, p. 1612; HaAN, Sarah (2000). "The persuasion route of the Law: advertising and legal persuasion”. Columbia Law Review, Vol. 100, N 5, pp. 1281-1326; Martín García, María del Lirio (2002). La publicidad. Su incidencia en la contratación. Madrid: Dykinson; STAZI, Andrea (2004). La pubblicità commerciale on line. Milán: Giuffrè Editore; Alonso Espinosa, Francisco José (2009). “Artículo 2". En LÁzaro Sánchez, Emilio (Coord.): Comentario a la Ley General de Publicidad. Navarra: Thomson Reuters y Civitas, pp. 27 y 28. 
virtud de la labor promocional. En efecto, en el sistema económico competitivo en el que se encuentran los empresarios, en pugna constante con sus restantes competidores, los mismos se esfuerzan, a través de los medios a su alcance, en captar, en el seno de la amplia masa de consumidores potenciales, el mayor número posible de consumidores y/o usuarios de sus bienes y/o servicios.

A través de esta última -la persuasión-, el fenómeno publicitario presenta connotaciones de agresividad, dado que, en la actualidad, la competencia económica de los empresarios se realiza a través de la publicidad $^{41}$. La finalidad persuasiva, propia del denominado modo publicitario, como modalidad formal típica de los mensajes publicitarios, menoscaba la objetividad, que es característica de la información, aunque el predominio de una u otra dimensión dependen de la expresión publicitaria concreta. En esta línea, cierto sector de la doctrina apunta que, frente a los mensajes puramente informativos, la comunicación publicitaria actual va unida a una intensa actividad creativa ${ }^{42}$.

La persuasión puede definirse como un proceso por el que el comunicador intenta influir en las creencias, las actitudes y la conducta de otra persona o grupo de personas mediante la transmisión de un mensaje frente al cual el destinatario mantiene la libertad de elección. Persuadir, en todo caso, no significa mentir, engañar o manipular. En efecto, debe reputarse como una sugerencia o un consejo. A través de la persuasión, se influye en el receptor del mensaje, pero no se determina su voluntad.

Ahora bien, frente al modelo de publicidad centrado en informar y persuadir a los destinatarios sobre la primacía de los bienes y/o servicios del anunciante frente a los de otros, en la actualidad, adquiere enorme importancia las estrategias publicitarias en la Red que, precisamente, buscan que los potenciales consumidores y/o usuarios -o, en términos generales, los comúnmente denominados internautas- tengan la impresión de que la empresa anunciante tiene un proyecto de futuro y, a su vez, es dinámica. Para alcanzar tal extremo, en Internet, se recurre, en gran medida, a anuncios caracterizados por su originalidad ${ }^{43}$.

El consumidor debe tener la posibilidad de elegir, pero, para ello, debe ser informado correcta y completamente de los productos y/o servicios que están a su disposición en el mercado. Solo, de este modo, los

41 Beater, Axel (2000). "Zum Verhältnis von europäischen und nationnalen Wettbewerbsrecht (Überlegungen am beispiel des schutzes vor irreführender werbung und des verbraucherbegriffs)". GRUR Int., No 1, pp. 965 y 966; Spang, Kurt (2005). Persuasión. Fundamentos de retórica. Pamplona: Eunsa, pp. 167 y 168.

42 Bassat, Luis (2003). El libro rojo de la publicidad. Barcelona: Planeta, p. 50.

43 Hall, Mark (1997). "Four models on how advertising works". Commercial Communications. The Journal of Advertising and Marketing Policy and Practice in the European Community, $\mathrm{N}^{\circ}$ 9, p. 13. 
ciudadanos podrán formar su voluntad como consumidores y tomar las decisiones que estimen más adecuadas.

A todo ello, además, se une el hecho de que en Internet se recurre, con cierta frecuencia, a fórmulas que, en muchos casos, pueden vulnerar la privacidad de los usuarios. Nos referimos, entre otros aspectos, a la publicidad comportamental en base a la que el destinatario de determinadas ofertas comerciales recibe mensajes comerciales altamente personalizados adaptados a sus gustos y preferencias ${ }^{44}$. No en vano los mismos se basan en la monitorización que, durante cierto espacio de tiempo, se efectúa del usuario al que se dirigen ${ }^{45}$. El contenido del mensaje, en relación a determinados bienes y/o servicios de interés para el usuario, seduce al mismo, determinando la contratación. Igualmente, en otros casos, se recurre a la denominada geolocalización cuyas comunicaciones comerciales dependen del lugar en el que, en cada momento, se encuentre el usuario ${ }^{46}$. No debe, en absoluto, permitirse que la aplicación de las nuevas tecnologías suponga para el consumidor y/o usuario un menoscabo de sus derechos de carácter fundamental. Este tipo de actuación -la publicidad de tipo comportamental o basada en el comportamiento del usuario- resulta especialmente visible al hilo de las actuaciones que vienen suscitándose en el ámbito de los buscadores. De hecho, estos últimos requieren a sus usuarios registrarse para disfrutar, además de servicios de búsqueda, de otros como el de correo electrónico, páginas personales, el historial de búsquedas y otras prestaciones complementarias de la denominada Web 2.0 (por ejemplo, los blogs). De este modo, podría haber un registro de las actividades que el usuario acomete en la Red, permitiendo, de esta manera, realizar perfiles de este y emplearlos por la empresa. En todo este orden de cuestiones, puede acontecer que el usuario no fuera consciente ni estuviera suficientemente informado de esta circunstancia. Con buen criterio, el legislador, comunitario y europeo, a través de la normativa legal, trata de imponer ciertas restricciones a las prácticas mencionadas, si bien, con carácter complementario, se fomenta el recurso a la autorregulación de la industria ${ }^{47}$. Esta última debe coadyuvar a elevar el nivel de

44 Sobre esta materia, véase López Jiménez, David y Martínez López, Francisco José (2010). "Nuevas coordenadas en el ámbito de la Web 2.0: el caso de la publicidad comportamental". Revista de Estudios Económicos y Empresariales de la Universidad de Extremadura, № 22, pp. 99-134.

45 Podría decirse, en cierta medida, que estamos pasando de la publicidad comportamental a la publicidad emocional que representa un paso más en la misma. En este sentido, recientemente se ha creado una patente de Microsoft que consiste en un sistema que escanea nuestros mensajes en las redes sociales -entre las que naturalmente está Facebook- deduciendo, de esta manera, el estado de humor, intereses e incluso, por si fuera poco, la inteligencia de la persona de que se trate para ofrecerle mejores anuncios adaptados a tales parámetros. Respecto a este aspecto, López Jiménez, David (2012). "El servicio de geolocalización con fines comerciales como novedosa manifestación de la Web 2.0”. Revista Veritas, No 9, pp. 90-98.

47 En el ámbito de los buscadores destaca el caso de Google. En cuanto a este último, procede efectuar dos consideraciones. Por un lado, respeta el acuerdo marco de garantía de seguri- 
protección establecido en la legislación, superando, dicho sea de paso, la obsolescencia de carácter normativo.

Debe, finalmente, considerarse que en el ámbito publicitario o comercial confluyen, además de los intereses de los consumidores y/o usuarios, otros intereses adicionales susceptibles de tutela. En el seno de estos últimos cabe entender incluidos: los de los propios anunciantes, sus competidores, directos e indirectos, los de las agencias, los medios y, en definitiva, los del público o sociedad con carácter general. En base a cuanto comentamos, ha de entenderse que la normativa heterónoma aprobada por el legislador necesariamente ha de saber conjugar, de manera adecuada, los intereses a los que hemos hecho alusión. En caso contrario, nos encontraríamos ante una norma parcialmente concebida en la que, de este modo, al tutelar únicamente un solo tipo de interés, los demás, como puede inferirse, quedarían a un lado y, en cierta medida, descuidados.

De acuerdo con el art. $51^{48}$ de la Constitución Española ${ }^{49}$, los poderes públicos deben garantizar la defensa de los consumidores y usuarios, protegiendo, mediante procedimientos eficaces, la seguridad, la salud y los legítimos intereses económicos de los mismos. A fecha de hoy, el Real Decreto Legislativo español 1/2007, de 16 de noviembre, por el que se aprueba el Texto Refundido de la Ley General para Defensa de los Consumidores y Usuarios y otras Leyes complementarias ${ }^{50}$, desarrolla el citado texto constitucional, fijando el marco básico para tal tutela. Aunque la Ley General de Publicidad, texto que, en su origen, data de 1988, no hace alusión expresa al artículo 51 de la Constitución Española ${ }^{51}$, debe reputarse que ha de considerarse ilícita la publicidad que violente la defensa de los consumidores y/o usuarios.

dad -Safe Harbor Framework - entre Estados Unidos y la Unión Europea, así como con el acuerdo marco de garantía de seguridad -Safe Harbor Framework- entre Estados Unidos y Suiza. Por otro, el citado buscador es parte de sugerentes iniciativas de autorregulación. En este sentido, entre otras, es miembro de la iniciativa publicitaria -Network Advertising Initiative (NAI)-, una asociación empresarial que tiene como finalidad establecer políticas responsables en materia de publicidad en el ámbito de Internet. Igualmente, cumple los siguientes códigos de conducta: el Código de Buenas Prácticas sobre Publicidad Online Basada en el Comportamiento del Internet Advertising Bureau del Reino Unido, el Código Australiano de Buenas Prácticas sobre Publicidad Online Basada en el Comportamiento y el Código Europeo de Autorregulación para la Publicidad Online Basada en el Comportamiento, de IAB Europe.

48 Constituye un principio rector de la política social y económica, bajo cuya observancia el Gobierno del Reino de Espańa debe regir todas sus actuaciones.

49 La relación que, de alguna manera, concurre entre publicidad y consumidor estaba contemplada, de una forma más clara, tanto en el proyecto como en el anteproyecto de la Constitución Española de 1978 actualmente vigente (BOE núm. 311 de 29 de diciembre de 1978).

50 BOE núm. 287 de 30 de noviembre de 2007.

51 Ahora bien, sí se refiere al mismo la Ley General para Defensa de los Consumidores y Usuarios refundida en el documento antes mencionado (Real Decreto Legislativo espańol $1 / 2007$, de 16 de noviembre). 
Asimismo, el art. 38 de la Constitución Española proclama la libertad de empresa en el marco de la economía de mercado. A pesar de que se reconoce a todo ciudadano el derecho o facultad de acometer una actividad económica o empresarial, este derecho no es ni mucho menos absoluto o ilimitado. En efecto, existen límites que deben ser necesariamente observados en su ejercicio. Se trata, entre otros, de la competencia ilícita, la usurpación de los derechos de propiedad industrial, la competencia desleal, así como una modalidad de esta última, cual es la publicidad ilíci$\mathrm{ta}^{52}$. En este sentido, aun reconociendo la absoluta idoneidad que ostenta la publicidad como herramienta de competencia, la necesidad de tutelar a los consumidores y/o usuarios, observando los imperativos constitucionales y de garantizar el mantenimiento de la lealtad, determina que sea necesario aprobar ciertas normas legales de derecho imperativo. En base a estas últimas, la publicidad se adecuará a dicha realidad, sancionándose, a este respecto, los ilícitos que tengan lugar en el uso de la misma.

\section{3) LA REMISIÓN DE COMUNICACIONES COMERCIALES ELECTRÓNICAS NO SOLICITADAS}

Al igual que acontece en el mundo tradicional, también en el espacio virtual, aunque, por sus circunstancias concomitantes, en mayor medida, se remiten numerosos mensajes comerciales ${ }^{53}$ a personas que, con carácter previo, no han manifestado su previo y expreso consentimiento. En el presente apartado, nos referiremos, en primer término, a la delimitación conceptual de este sugerente y frecuente fenómeno. En segundo lugar, aludiremos a las opciones o sistemas imperantes en los diferentes Estados por lo que al posible envío de las comunicaciones promocionales se refiere $\left(o p t\right.$-in y $\left.o p t-o u t^{54}\right)$. En tercer y último lugar, al hecho de que, a tenor del

52 En el caso concreto de Chile, la actividad comercial debe observar las normas y principios constitucionales y legales, entre las que deben considerarse comprendidas las normas presentes en la ley 19.496 de protección al consumidor. Aunque esta última, se refiere, con carácter general, a la actividad publicitaria, también establece y sanciona la publicidad ilícita.

53 En cualquier caso, existen programas informáticos, como AdBlock, que se erigen como una suerte de extensiones de los navegadores susceptibles de bloquear todo tipo de inserciones publicitarias. Coexisten con otras opciones diversas - no vinculadas con la anterior-, que han optado por financiarse parcialmente cobrando a los anunciantes con el objetivo de posibilitar que sus anuncios se salten sus filtros siempre que observen un conjunto de estándares. Este tipo de técnicas coexisten con otras más antiguas cual, por ejemplo, son: los cancelbots que borran automáticamente los avisos múltiples insertados, por los spammers, en grupos de discusión.

54 Las leyes que funcionan en base al sistema opt-out permiten la remisión de comunicaciones comerciales no deseadas salvo que el receptor le haya informado que bien no quiere continuar recibiendo correos -opt-out específico- bien el receptor se haya incluido en una lista específica de oposición (registros de opt-out) en virtud de la cual se informa a los emisores de publicidad que ese individuo no desea recibir comunicaciones comerciales. 
Derecho español y europeo, la práctica reiterada de este tipo de conductas puede determinar que las mismas sean reputadas una práctica comercial desleal por acoso.

\section{1) CONCEPTO}

Se entiende por spam toda aquella comunicación publicitaria no solicitada (que, normalmente, tiene como fin ofertar, comercializar o tratar de despertar el interés de un determinado producto, servicio y/o empre$\mathrm{sa}^{55}$ ) que llegue tanto al buzón de correo electrónico ${ }^{56}$-que representa uno de los instrumentos más utilizados de Internet- como a otros espacios diversos ${ }^{57}$. Otro de los caracteres más notables de tal práctica es la difusión masiva del mensaje publicitario que la comunicación incluye ${ }^{58}$.

El término spam o spamming-pourriel en francés- tiene su origen en una práctica antigua en los países anglosajones, en virtud de la cual se regalaba un jamón de escasa calidad ${ }^{59}$-spiced ham- junto con las compras que se efectuaban en las carnicerías, haciéndose, de esta forma, mención de un producto recibido sin ser, en principio, deseado ${ }^{60}$.

55 Ahora bien, como determina Jijena Leiva, Renato (2010). "Spam y Derecho. Consideraciones críticas sobre la regulación de las comunicaciones comerciales por correo electrónico en las leyes 19628 y 19946". Memorias del XIV Congreso Iberoamericano de Derecho e Informática. Monterrey: Instituto de Investigaciones Jurídicas de la UNAM, pp. 433, 434 y 441, puede tener, además, otros fines diversos a la promoción de bienes y/o servicios.

Burgos y Luz De León, Daniel (2001). Comercio electrónico, publicidad y marketing en Internet. Madrid: McGraw-Hill, p. 24; Miquel Rodríguez, Jorge (2001). "Problemática jurídica de la publicidad en Internet”. En Botana García, Gema Alejandra (Coord.): Comercio Electrónico y Protección de los Consumidores. Madrid: La Ley, pp. 245-274; Tato Plaza (2004) 89-104; Tato Plaza, Anxo (2004). "La publicidad en Internet". En Moro Almaraz, María Jesús (Dir.) y Aparicio Vaquero, Juan Pablo y Batuecas Caletrío, Alfredo (Coords.): Autores, consumidores y comercio electrónico. Madrid: Colex y Caja Duero, pp. 141-156; Guillén Catalán, Raquel (2005). Spam y comunicaciones comerciales no solicitadas. Navarra: Thomson Aranzadi, p. 76; Vidal Portabales, José Ignacio (2010). "Algunas notas sobre formación y perfección de los contratos electrónicos en la Ley 34/2002, de 11 de julio (LSSI Y CE)”. En Gómez Segade, José Antonio y García Vidal, Ángel (Coords.): El Derecho mercantil en el umbral del siglo XXI. Libro homenaje al Prof. Dr. Carlos Fernández-Novoa en su octogésimo cumpleaños. Madrid-Barcelona: Marcial Pons, pp. 667 y 668.

57 Schryen, Guido (2007). "Anti-spam legislation: An analysis of laws and their effectiveness". Information \& Communications Technology Law, Vol. 16, № 1, pp. 17-32.

58 Ahora bien, puede plantearse la duda de qué debe entenderse por masivo. Sobre la interpretación que cabe, a este respecto, véase De la MAZa Gazmuri, I. (2002). "El correo en los tiempos de Internet". Anuario de Filosofía Jurídica y Social No 20, pp. 261-321.

59 Una de sus principales características, que precisamente lo hacían atractivo, era que no precisaba refrigeración. No en vano, este tipo de carne, producida por Hormel Foods con posterioridad a 1926, fue bastante consumida por el ejército durante la Segunda Guerra Mundial.

60 Sampol Pucurrull, Miguel (2005). “Administración Electrónica”. En De Fuentes Bardají, Joaquín (Dir.) y Pereña Pinedo, Ignacio (Coord.): Manual de Derecho 
A pesar de que hace unos años había quien pronosticaba un posible fracaso del spam ${ }^{61}$, la realidad es otra, pues el recurso a semejante práctica comercial, claramente invasiva de la intimidad ${ }^{62}$, desde la primera vez que se empleó en Estados Unidos a mediados de la década de los noventa del siglo pasado ${ }^{63}$, cada vez es mayor. Las posibles razones que explican la extraordinaria proliferación de este tipo de mensajes ${ }^{64}$ son, entre otras, la falta de consenso internacional -traducida en un trato legislativo diferente $\mathrm{o}$, incluso, inexistente-, posibilidad de llegar a un amplísimo número de potenciales clientes a los que los spammers no accederían de otro modo, facilidad en la utilización de recursos tecnológicos que ocultan o falsifican la identidad de los remitentes y permiten realizar envíos masivos, y bajos costes.

Bajo el concepto de spam se incluyen diversas formas de emisión de mensajes comerciales no demandados por su destinatario que pueden llegar al mismo por correo electrónico, vía móvil -SMS o MMS- o por mensajería instantánea -en cuyo caso se denomina spim ${ }^{65}-$, e, incluso, por bluetooth-bluespam-, si bien nos centraremos, fundamentalmente, en el estudio de las comunicaciones comerciales por correo electrónico. También ha llegado al popular Whatsapp que, como es sabido, es un servicio de mensajería instantánea vinculado al número de teléfono móvil. Habida cuenta de la progresiva e incesante popularidad de Whatsapp, su disponibilidad multiplataforma en sistemas iOS, Android, Windows Phone, Symbian o Blackberry OS, y sus posibilidades de envío de imágenes, vídeo, texto o audio, podemos concluir que la aplicación de mensajería será

Administrativo Sancionador. Navarra: Thomson Aranzadi y Ministerio de Justicia, pp. 17531776.

61 Gauthronet, Serge y Drouard, Etienne (2001). Communications commerciales NonSollicitées et Protection des Données. Bruselas: Internal Market DG-Contract, p. 14.

62 Ruiz Miguel, Carlos (2001). "Protección de datos personales y comercio electrónico". En Gómez Segade, José Antonio (Dir.): Comercio electrónico en Internet. Madrid: Marcial Pons, pp. 408 y 409; Tato Plaza (2001) 222-223.

63 El primer caso que suele citarse, a propósito del spam, fue el de dos abogados de Arizona -Laurence Canter y Martha Siegel- que, en dicha fecha, publicitaron sus servicios, utilizando, para ello, grupos de discusión Usenet.

64 Tales ventajas han sido enunciadas por determinados autores. Así, entre otros muchos, Del Peso Navarro, Emilio (2003). Servicios de la Sociedad de la Información. Madrid: Díaz de Santos, p. 265; Durán Alba, Juan Fernando (2006). "El derecho a la libertad informática (según el art. 18.4 CE) como límite al correo electrónico no solicitado”. En Carrasco Durán, Manuel; Pérez Royo, Javier; Urías Martínez, Joaquín Pablo y Terol Becerra, Manuel (Coords.): Derecho constitucional para el siglo XXI: actas del VIII Congreso Iberoamericano de Derecho Constitucional. Navarra: Aranzadi, pp. 1539-1570.

65 Por lo que se refiere a la palabra spim, cabe seńalar que es una expresión constituida por las dos primeras letras de spam y las dos últimas de las instant messaging, por lo que esta práctica intrusiva también es conocida como Messenger Spam o spam up, ya que combina el envío masivo a direcciones IP, propio del spam, con la apertura de una ventana emergente, al estilo del pop up. Los mensajes emergen, de manera automática, en forma de $p \circ p$ up, después de que el usuario se haya autenticado en el programa de mensajería. 
utilizada ampliamente en el futuro próximo para distribución de malware $^{66}$. Por otro lado, los avances que las redes sociales y las plataformas colaborativas suponen, están modificando las prácticas comerciales, redefiniendo, de esta manera, la forma electrónica de ofertar bienes y/o servicios a través de la publicidad hipercontextualizada, según los perfiles de usuario, diversificando el mercado y creando nuevos canales de comunicación. Los spammers pueden utilizar la información personal disponible en las redes sociales para recopilar direcciones de correo electrónico, de modo que, cuando envíen spam, parezca que se envía desde los contactos directos ${ }^{67}$.

Respecto a las desventajas ${ }^{68}$ que esta práctica genera, además de la importante vulneración de la privacidad, entre otras, cabe destacar: la molestia personal de recibir información no deseada ni solicitada; la posibilidad de que el sistema de correo electrónico quede saturado; ralentización de la velocidad de la Red; el coste, económico y temporal, que supone la descarga de los mensajes electrónicos no solicitados ${ }^{69}$; posibilidad que el contenido del mensaje sea fraudulento; e incluya programas de carácter malicioso.

Antes de proceder al examen de la regulación de esta sugerente y habitual problemática, a propósito del Derecho español -sin perjuicio de las apreciaciones oportunas de Derecho comparado-, cabe insistir en el hecho de que representa una notable violación de la privacidad del usuario destinatario de este tipo de comunicaciones comerciales. Hay que defender con convicción, en virtud de la ley y de la autorregulación, la privacidad. Es intolerable tener que soportar una pérdida del nivel de protección de datos de carácter personal como consecuencia de la implantación de las nuevas tecnologías.

66 En cuanto a las vías en virtud de las que el malware -software malicioso o malintencionado-, puede actuar, entendemos que son dos. En primer lugar, a través de la recepción de spam cuyo mensaje incluya enlaces electrónicos a los que voluntariamente acceda su receptor y, en segundo lugar, mediante la navegación por sitios Web inseguros de los que el usuario pueda descargar determinados programas que contengan troyanos.

A propósito de este particular, véase el procedimiento sancionador 00663/2012, instruido por la Agencia Española de Protección de Datos (AEPD). En virtud del mismo, se castigó a la entidad demandada por una infracción del artículo 6 de la Ley Orgánica española 15/1999, de 13 de diciembre, de Protección de Datos de carácter Personal (LOPD) -respecto del consentimiento- en relación con el artículo 46 del Reglamento de la LOPD, tipificada como grave en el artículo 44.3 b) de dicha norma, una multa de seis mil euros de conformidad con lo establecido en el artículo 45 de la citada Ley Orgánica.

De Pablos Heredero, Carmen (2004). Informática y comunicaciones en la empresa. Madrid: Esic, p. 133; Sánchez del Castillo (2007) 326; Davara Rodríguez, Miguel Ángel (2009). "Acerca del spam”. El Consultor de los Ayuntamientos y de los Juzgados, $\mathrm{N}^{\circ}$ 13, p. 2.

69 Tales extremos fueron destacados, hace unos años, por la Cámara de Comercio de Santiago, con la finalidad de poner de manifiesto las molestias que este tipo de prácticas generan a sus destinatarios. 
En cuanto al concepto de privacidad, no parece sencillo dar, a priori, una definición de lo que debe entenderse por tal ${ }^{70}$. Una delimitación conceptual muy extendida, aunque ya superada, es la que, a finales del siglo XIX, pronunció el juez americano Cooley ${ }^{71}$ que manifestó que privacidad es el derecho a estar solo ${ }^{72}$, a estar en paz ("the right to be alone"). También se ha vinculado con el derecho al secreto, es decir, sería una suerte de ámbito de carácter vital cuyo acceso estaría limitado para los demás ${ }^{73}$. Se trataría, en este sentido, de que ciertos aspectos sean opacos para los ter$\operatorname{ceros}^{74}$, pues su conocimiento podría suscitar cierta consternación, moral o psíquica, al potencial afectado ${ }^{75}$. La definición concreta que, al respecto, se enuncie dependerá, en gran medida, de la denominación específica que se haya acuñado para determinar el derecho al que nos referimos: la protección de datos de carácter personal. Lo importante, más que el nomen iuris, es que nos hallamos en el ámbito de un derecho fundamental cuyo contenido jurídico está formado por los diferentes instrumentos que integran la protección de los datos de carácter personal que posee un núcleo o reducto indisponible incluso para el legislador. En cualquier caso, se ha dicho ${ }^{76}$, con acierto, que dentro del mismo puede considerarse incluido el derecho a ser dejado solo, el derecho a tomar decisiones personales, el derecho al control de la información personal, el derecho a la inaccesibilidad, el derecho a excluir a terceros de la información personal y el derecho sobre el acceso cognoscitivo.

Las políticas de privacidad realizadas por parte de los prestadores de servicios de la sociedad de la información que operan en Internet, en múltiples escenarios, constituyen uno de los puntos jurídicos relevantes que deben ser tenidos en consideración para desarrollar numerosas actividades susceptibles de ser conceptualizadas en el ámbito de la publicidad interactiva, la contratación electrónica y otras muchas conexas con las mismas. Su importancia va mucho más allá del simple cumplimiento de

\footnotetext{
70 Ugarte Cataldo, José Luis (2011). "Privacidad, trabajo y derechos fundamentales". Estudios Constitucionales, $\mathrm{N}^{\circ} 1$, p. 16.

71 Cooley, Thomas (1888). A Treatise on the Law of Torts or the Wrongs which arise independent of contract. Chicago: Callaghan, p. 29; Brandeis, Samuel y Warren, Louis (1890). "The right to privacy", Harvard Law Review, No 5, p. 3.

72 Aunque la privacidad puede entenderse de este modo, ha de considerarse, igualmente, que la persona no es un ente aislado, sino que se integra dentro de un contexto social, que es donde realmente adquiere sentido.

73 En sentido similar, Carbonnier Jean (1965). Derecho Civil, Tomo 1. Barcelona: Bosch, p. 239.

74 Cierto sector de la doctrina se refirió al derecho a la opacidad. Así, Peña González, Carlos, (1999). "Notas sobre las relaciones entre privacidad y autonomía". Revista Jurídica de la Universidad de Palermo, No 19, p. 70.

75 Novoa Monreal, Eduardo (1977). Derecho a la vida privada y libertad de información. Santiago: Siglo XXI Editores, p. 46.

76 Corral Talciani, Hernán (2000). "Configuración Jurídica del derecho a la privacidad II: concepto y delimitación”. Revista Chilena de Derecho, N², pp. 331-335.
} 
la legalidad vigente. En efecto, con las mismas no se trata únicamente de garantizar el cumplimiento de un conjunto de obligaciones normativas, pues su contenido, en numerosas ocasiones, va más allá de las mismas, cubriendo un cierto vacío legal. Tal extremo puede vincularse, no solo a la labor de promoción que el legislador efectúa por lo que a la autorregulación respecta ${ }^{77}$-de la que la política de privacidad es una manifestación-que veremos más adelante, sino a que las propias empresas valoran, de manera importante, la preocupación que los ciudadanos en general manifiestan respecto a su privacidad ${ }^{78}$, cuestión vinculada, en no pocas ocasiones, con la seguridad ${ }^{79}$.

\section{2) EL SISTEMA DE INCLUSIÓN VOLUNTARIA VS. EXCLUSIÓN VOLUNTARIA}

Los Estados ${ }^{80}$ que decidan combatir legislativamente el spam deberán, previamente, decidir si optan por un sistema opt-in (consentimiento expreso o inclusión voluntaria) u opt-out (oposición explícita o exclusión voluntaria). El primero -opt-in-, únicamente permite el envío de comunicaciones comerciales a quienes hubieran manifestado su consentimiento

77 Sobre esta cuestión, y las consideraciones efectuadas respecto a Chile, véase el sugerente estudio de Cerda Silva, Alberto (2006). "Algunas consideraciones sobre los códigos de conducta en la protección de los datos personales". Revista Chilena de Derecho Informático, $\mathrm{N}^{\circ}$ 8, pp. 121-132.

78 Fruto de tal preocupación, cabe, asimismo, referirse a otras iniciativas no menos sugerentes como la denominada Web of Trust -extensión posible para ciertos navegadores-, que constituye una comunidad dedicada a clasificar los sitios Web en función de una serie de parámetros, como, entre otros, son la fiabilidad del vendedor, la privacidad y el tipo de contenido. La extensión a la que nos referimos muestra la reputación de un determinado sitio Web como un icono de semáforo junto a los resultados de las búsquedas realizadas. Un semáforo verde quiere decir que los usuarios lo han valorado como fiable y de confianza. Ahora bien, el rojo advierte sobre posibles amenazas y el naranja significa que se debe ser relativamente prudente al usar un concreto sitio Web.

79 En este sentido, recientemente, los buscadores están comenzando a filtrar sus resultados al detectar contenidos potencialmente peligrosos. Así, a título de ejemplo, Google utiliza los datos de StopBadware.

80 En el escenario europeo se han aprobado diversas normas para hacer frente al spam. En este sentido, cabe destacar, entre otros países, a: Bélgica: art. 14 Loi sur certains aspects juridiques des services de la société de l'information (de 11 de marzo 2003); Dinamarca: art. 6 Marketing Practices Act (de 25 de julio de 2003); Irlanda: art. 13 Statutory Instruments $\mathrm{N}^{\circ} 535$ (de 6 de noviembre de 2003); Italia: art. 10 Decreto Legislativo $N^{\circ} 185$, de 22 mayo 1999, y Sección 13 Decreto Legislativo No 196, de 30 junio de 2003 (Codice in materia di protezione dei dati personali); Portugal: art. 22 Decreto-Lei $\mathrm{N}^{\circ}$ 7/2004 (de 7 de enero de 2004); y Reino Unido: art. 22 Statutory Instruments $\mathrm{N}^{\circ} 2426$ (de 11 de diciembre de 2003). 
previo y específico. El sistema $o p t$-out $t^{81}$ consiente realizar comunicaciones comerciales, salvo que el destinatario manifieste su rechazo ${ }^{82}$.

A nuestro entender, el sistema de consentimiento expreso, aplicado en el momento de la recogida, posibilita el que se puedan obtener los datos personales y, además, permite que el eventual destinatario pueda conocer las condiciones delimitadas para su tratamiento. La transparencia inherente al mecanismo del consentimiento previo, a nuestro juicio, debería generalizarse en la actualidad.

Consideramos que debe reputarse perjudicial, para la consolidación del comercio electrónico, el hecho de que los internautas puedan cuestionarse la lealtad del comerciante en el momento de la contratación de un determinado bien y/o servicio.

Como seguidamente veremos, el sistema $o p t$-in es el vigente en el escenario comunitario $-\mathrm{y}$, por ende, español ${ }^{83}-$, mientras que el opt-out resulta imperante en el espacio estadounidense ${ }^{84}$. Repárese en que la divergencia normativa existente entre Norteamérica y Europa suscita un importante incremento del uso del correo electrónico para la remisión de spam. En consecuencia, es de imperiosa necesidad la cooperación entre los Estados $^{85}$, para, precisamente, adoptar un acuerdo de alcance internacional cuyo articulado, en primer lugar, contemple los principios generales comunes que necesariamente deberán cumplir las comunicaciones co-

81 Como dispone cierto sector de la doctrina -Hafner, Katie (2003). "A Change of Habits To Elude Spam's Pull”. The New York Times, 23 de octubre, pp. 1-3-, el hecho de manifestar el rechazo expreso en este sistema puede suponer, en ciertas ocasiones, la recepción de más spam. Dejando al margen los concretos efectos generales de carácter negativo, cabe insistir en las molestias que la implantación de tal sistema puede determinar. En este sentido, Muñiz Espada, Esther (2003). "Algunas consideraciones sobre la nueva Ley de Servicios de la Sociedad de la Información y de Comercio Electrónico". En Cabanillas Sánchez, Antonio (Coord.): Estudios Juridicos en homenaje al profesor Luis Diez-Picazo. Madrid: Thomson Civitas, p. 2686.

82 Rodríguez Casal, Carlos y Loza Correa, María (2002). "Protección de la privacidad. Aproximación al opt-in/opt-out". Revista de la Contratación Electrónica, N 23, pp. 3-18.

83 Respecto al caso concreto de Espańa, cabe precisar que a los prestadores de servicios establecidos en un Estado no perteneciente a la Unión Europea o al Espacio Económico Europeo que no dirijan sus servicios concretamente al territorio español no les resultará de aplicación el régimen sancionador establecido en el Título VII de la LSSI-CE.

84 Tal sistema también podría estar, en cierta medida, vigente en Chile. Tal apreciación puede sostenerse a tenor del art. 28 b) de la Ley 19.496, sobre Protección de los Derechos de los Consumidores, que dispone que "toda comunicación promocional o publicitaria enviada por correo electrónico deberá indicar la materia o asunto sobre el que versa, la identidad del remitente y contener una dirección válida a la que el destinatario pueda solicitar la suspensión de los envios, que quedarán desde entonces prohibidos". Esta última apreciación, contemplada en la norma legal, es relevante. Además de cuanto se comenta, debe seńalarse que, en ocasiones, el hecho de que el titular solicite ser removido de una base de datos, permite que el emisor pueda verificar que el receptor tiene la cuenta de correo activa, lo que, en cierta medida, valoriza su base de datos.

85 Así, Rothchild, John (1999). "Protecting the Digital Consumer: The Limits of Cyberspace Utopianism”. Indiana Law Journal, No 3, p. 893. 
merciales electrónicas y, en segundo lugar, establezca en cada Estado una autoridad pública con competencias similares respecto al control de este tipo de prácticas.

\subsection{1.) La regulación en el plano comunitario}

Han sido muchos los progresos legislativos que, desde las instituciones europeas, se han introducido para regular el tratamiento de los datos personales ${ }^{86}$. Así, desde la Directiva europea 95/46/CE relativa a la protección de datos personales ${ }^{87}$, se han aprobado nuevos textos legales que han configurado en el ámbito de la Unión Europea un marco jurídico de protección de datos personales en las comunicaciones electrónicas. Igualmente, cabe considerar que, en el año 2000, se refirió a esta sugerente cuestión el Grupo del Artículo $29^{88}$ en varios documentos (así destaca el documento en el que aborda el respeto de la intimidad en Internet, adoptado el 21 de noviembre de 2000) en los que se pronunciaba sobre la prospección publicitaria no deseada. En este sentido, además de la Directiva 2000/31 sobre comercio electrónico ${ }^{89}$, se ha aprobado la Directiva $2002 / 58$ sobre la privacidad y las comunicaciones electrónicas ${ }^{90}$, la Directiva 2005/29 sobre prácticas comerciales desleales ${ }^{91}$ y, más recientemente, la Directiva 2006/24 de conservación de datos de tráfico ${ }^{92}$.

Por lo que a la Directiva sobre comercio electrónico se refiere, cabe destacar que deja a la decisión de cada Estado la posibilidad de admitir o

86 Sin perjuicio de que esencialmente nos referiremos al escenario europeo y, por ende, español, cabe manifestar que en Chile, en toda esta materia, se encuentra vigente la Ley 19.628 sobre protección de datos de carácter personal que ha sido modificada, desde su aprobación en 1999, en diversas ocasiones -la última, en 2012, por parte de la Ley 20575-. Debe destacarse que tal norma legal, pionera sobre tal ámbito en toda América Latina, disciplina aspectos que se encuentran relacionados con los derechos a la vida privada e intimidad que se encuentran garantizados en los apartados 4 y 5 del art. 19 de la Constitución chilena de 1980. Sobre las críticas a dicha norma legal, puede verse el trabajo de Jijena Leiva, Renato (2010). "Actualidad de la protección de datos personales en América Latina. El caso de Chile”. Memorias del XIV Congreso Iberoamericano de Derecho e Informática. Monterrey: Instituto de Investigaciones Jurídicas de la UNAM, pp. 413-431.

87 Diario Oficial ${ }^{\circ}$ L 281 de 23 de noviembre de 1995.

88 En base al artículo 29 de la Directiva 95/46/CE -Diario Oficial n ${ }^{\circ}$ L 281 de 23 de noviembre de 1995- se creó un grupo constituido por diversos representantes de las autoridades nacionales encargadas de la protección de los datos personales. Este grupo es un órgano asesor relativo a la protección de los datos personales, independiente de las instituciones de la Unión Europea.

89 Diario Oficial $\mathrm{n}^{\circ} \mathrm{L} 178$ de 17 de julio de 2000.

$90 \quad$ Diario Oficial n ${ }^{\circ} \mathrm{L} 201$ de 31 de julio de 2002.

91 Diario Oficial $\mathrm{n}^{\circ} \mathrm{L} 149$ de 11 de junio de 2005.

92 Diario Oficial n ${ }^{\circ} \mathrm{L} 105$ de 13 de junio de 2006. En relación a tal norma, puede verse Vilasau, Mònica (2006). "La Directiva 2006/24/CE sobre conservación de datos del tráfico en las comunicaciones electrónicas: seguridad v. privacidad”. Revista de los Estudios de Derecho y Ciencia Politica de la UOC, N³, pp. 1-15. 
no el spam. En el supuesto de que opte por su licitud, habrá de establecer ciertos presupuestos. En este sentido, las comunicaciones comerciales electrónicas deberán estar identificadas como tales de manera clara e inequívoca. De igual modo, los anunciantes deberán informarse y respetar las listas opt-out para no remitir comunicaciones a los usuarios que se hayan opuesto. También indicaba que las comunicaciones promocionales no deseadas no debían redundar en gastos complementarios para los usuarios.

Debe advertirse que el articulado de la Directiva sobre comercio electrónico no establecía la necesidad de que el destinatario manifestara, de manera libre e inequívoca, su voluntad respecto al envío de las comunicaciones comerciales. Tanto este como otros aspectos relevantes determinaron la aprobación de la Directiva comunitaria 2002/58 que modifica la antes enunciada. Entre las reformas que se operaron, cabe destacar fundamentalmente tres. En primer lugar, se enumeraron los medios por los que puede acometerse la venta directa, a saber: la llamada automática sin intervención humana, el fax y el correo electrónico. En segundo lugar, para la remisión de comunicaciones comerciales, a través de los medios anteriores, el receptor habrá tenido que manifestar previamente su consentimiento con una excepción. Esta última supone que no será necesaria la prestación del consentimiento, por parte del sujeto receptor, cuando anteriormente haya sido cliente de una determinada entidad, cumpliéndose, además, ciertos presupuestos -solicitud directa del titular de la dirección de correo electrónica; que los bienes y/o servicios respecto de los que se realiza la promoción estén relacionados con los que el usuario contrató previamente; y que, en las comunicaciones comerciales recibidas, se informe de la posibilidad de oponerse a envíos posteriores-. En tercer y último término, se prohíbe la remisión de comunicaciones comerciales por parte de empresas que oculten su identidad.

\subsection{2.) La regulación en el ámbito español}

A nivel español, el spam es objeto de prohibición ${ }^{93}$ en el art. 21 de la LSSI-CE, en los siguientes términos: "1. Queda prohibido el envío de

93 En Chile, sin embargo, no existe normativa legal alguna que limite y, en su caso, impida la remisión de comunicaciones comerciales no solicitadas. Aunque la citada Ley 19.628 sobre protección de datos de carácter personal, considera la posibilidad de oponerse a la utilización de datos personales con fines publicitarios, paradójicamente, no se incluye mecanismo alguno que establezca la obligación de que una entidad proceda a eliminar de sus registros los datos en cuestión. Por si eso fuera poco, la citada norma legal no señala nada respecto a la recepción no consentida de correos electrónicos, por lo que no puede apreciarse infracción alguna por parte de quienes efectúan dichos envíos. Asimismo, el tratamiento de datos personales que provengan de fuentes accesibles al público no requiere autorización en el supuesto de que indiquen ciertos antecedentes como profesión, actividad, 
comunicaciones publicitarias o promocionales por correo electrónico u otro medio de comunicación electrónica equivalente que previamente no hubieran sido solicitadas o expresamente autorizadas por los destinatarios de las mismas; 2. Lo dispuesto en el apartado anterior no será de aplicación cuando exista una relación contractual previa, siempre que el prestador hubiera obtenido de forma lícita los datos de contacto del destinatario y los empleara para el envio de comunicaciones comerciales referentes a productos o servicios de su propia empresa que sean similares a los que inicialmente fueron objeto de contratación con el cliente. En todo caso, el prestador deberá ofrecer al destinatario la posibilidad de oponerse al tratamiento de sus datos con fines promocionales mediante un procedimiento sencillo y gratuito, tanto en el momento de recogida de los datos como en cada una de las comunicaciones comerciales que le dirija". Añade el último párrafo del mencionado precepto, tras la reforma de $2012^{94}$, que "cuando las comunicaciones hubieran sido remitidas por correo electrónico, dicho medio deberá consistir necesariamente en la inclusión de una dirección electrónica válida donde pueda ejercitarse este derecho, quedando prohibido el envio de comunicaciones que no incluyan dicha dirección".

A tenor de lo establecido en la primera parte del art. 21.2 de la LSSI$\mathrm{CE}^{95}$, podemos determinar que la remisión de comunicaciones comerciales, en tal supuesto, será lícita siempre que concurran, con carácter necesario, los siguientes presupuestos ${ }^{96}$ :

1. Que exista una relación contractual previa que no es necesario que subsista en el momento de operarse la comunicación. La disposición que comentamos alude a una relación contractual perfeccionada $y$

títulos educativos, dirección o fecha de nacimiento, o sean necesarios para comunicaciones comerciales de respuesta directa o comercialización o venta directa de bienes o servicios. Esta última apreciación, contemplada en el art. 4, párrafo 4, de la Ley 19.628 propicia, por llamativo que pueda resultar, el spam.

94 Ańadido por el Real Decreto Ley español 13/2012, de 30 de marzo, por el que se transponen Directivas comunitarias en materia de mercados interiores de electricidad y gas y en materia de comunicaciones electrónicas, y por el que se adoptan medidas para la corrección de las desviaciones por desajustes entre los costes e ingresos de los sectores eléctrico y gasista -publicado en BOE núm. 78 de 31 de marzo de 2012-.

95 Sobre los problemas de interpretación que tal norma suscita, en la práctica, puede verse Paniza Fullana, Antonia (2004). "Comunicaciones comerciales no solicitadas y marketing directo: el sistema opt out como excepción (correo electrónico y mensajes SMS con fines publicitarios)”. En Ramos, Benjamín y Ribagorda, Arturo (Dirs.): Avances en criptografía y seguridad de la información. Madrid: Díaz de Santos, pp. 437-445.

96 DE Asís Roig, Agustín (2004). "Comentarios a la Disposición Final Primera". En García de Enterría, Eduardo y de la Cuadra-Salcedo, Tomás (Coords.): Comentarios a la Ley General de Telecomunicaciones, Ley 32/2003, de 3 de noviembre. Navarra: Thomson Aranzadi, pp. $1205-1218$. 
ejecutada y no al simple contacto propio de la fase precontractual ${ }^{97}$ -donde deberán entenderse incluidas las intenciones de contratar, contratos previos no conclusivos o, qué duda cabe, tratos preliminares-.

2. Los datos de contacto con el destinatario deben haberse obtenido de forma lícita, lo que presupone, como regla general, el cumplimiento de los deberes de información al titular de los datos y de recabar el consentimiento del mismo para su tratamiento, salvo en los supuestos expresamente previstos en la legislación de protección de datos ${ }^{98}$.

3. Dichos datos únicamente pueden establecerse para el envío de comunicaciones comerciales referentes a productos y/o servicios de su propia empresa que sean similares a los que inicialmente fueron objeto de contratación con el cliente ${ }^{99}$. Esto último supone un doble condicionamiento:

a. De carácter subjetivo, en cuanto a que se trate de productos o servicios de la propia empresa. La legislación no aclara, en modo alguno, en qué sentido debe entenderse como productos propios de la empresa, lo que determina una gran inseguridad en cuanto a los límites de esta actividad al cubrir no solo la relación de

97 Rodríguez de las Heras Ballel, Teresa (2006). "La formación del contrato en el entorno electrónico y los procedimientos electrónicos de contratación”. En Calvo Caravaca, Alfonso Luis y Carrascosa González, Javier (Dirs.): Estudios sobre Contratación Internacional. Madrid: Colex, pp. 535-572. En sentido contrario, GuilléN Catalán, Raquel (2009). "Las comunicaciones comerciales en el marco de la contratación electrónica”. En Orduña Moreno, Javier y Aguilera Anegón, Gonzalo (Dirs.), y Plaza Penadés, Javier y Balluguera Gómez, Carlos (Coords.): Comercio, administración y registro electrónicos. Navarra: Thomson Reuters, p. 117, quien considera que deben entenderse incluidas las negociaciones preliminares.

98 Lo que no resulta lícito, a tenor de la normativa legal imperante, es que, aunque los datos (correos electrónicos propios y de terceros) hayan sido obtenidos de forma lícita, se incluyan en el apartado de destinatarios -en sede de "CC" y no "CCO", siendo, por ende, visibles para los demás destinatarios del propio mensaje- cuando se efectúe la remisión de la comunicación comercial. En toda esta materia debe considerarse aplicable el art. 10 de la LOPD -que contempla el deber de secreto sobre todo por parte del responsable del ficheroque tiene como objetivo evitar que, por parte de quienes están en contacto con los datos personales almacenados en ficheros, se efectúen filtraciones de los datos en modo alguno consentidas por los titulares de los mismos. El precepto citado se consideró vulnerado en el procedimiento sancionador 00629/2012, de la AEPD. De hecho, a tenor del art. 44.3.d) de la LOPD, en su redacción aprobada por Ley española 2/2011, de 4 de marzo, de Economía Sostenible (BOE núm. 55 de 5 de marzo de 2011), se califica como infracción grave: "la vulneración del deber de guardar secreto acerca del tratamiento de los datos de carácter personal al que se refiere el artículo 10 de la presente Ley". En sentido similar, entre otros, los procedimientos sancionadores 00018/2010, 00228/2010, 00588/2010, 00687/2010 y el 00559/2011 también de la AEPD.

99 En cuanto a la interpretación que debe darse a tales conceptos, véase Paniza Fullana, Antonia (2008). "Algunas reflexiones sobre la normativa aplicable a los contratos a distancia celebrados con consumidores: problemas y contradicciones". En Cotino Hueso, Lorenzo (Coord.): Consumidores y usuarios ante las nuevas tecnologías. Valencia: Tirant lo Blanch, pp. 78-82. 
producción, sino también de comercialización o distribución de productos. Lo que sí queda claro, no obstante, es que tales comunicaciones no podrán efectuarse con productos que no estén comprendidos en la actividad comercial de la empresa.

b. De naturaleza objetiva, ya que la norma legal española exige que los productos que puedan difundirse en este concepto estén, precisamente, relacionados con los que inicialmente fueron objeto del contrato. La Directiva sobre privacidad alude a "sus propios productos de características similares". No valdría, por tanto, cualquier producto de la misma marca, sino que necesariamente han de ser productos o servicios de características similares.

Resulta interesante incidir en que el art. 21 de la LSSI-CE no distingue, de manera clara, entre oferta de contrato y actividad publicitaria ${ }^{100}$. En este sentido, debemos poner de relieve que las restricciones que afectan a la actividad publicitaria no han de considerarse extensivas a la oferta y contraoferta de contrato, pues, si así fuere, el comercio electrónico sería, según tal opinión, de imposible o muy compleja práctica.

Existen dos máximas que, en relación con la remisión de comunicaciones comerciales, siguen vigentes, de acuerdo con la LSSI-CE, incluso después de su modificación. Por un lado, dichas comunicaciones realizadas por vía electrónica, se rigen por lo dispuesto en la LOPD, en lo que respecta a la obtención de datos, información a los interesados, y creación y mantenimiento de ficheros -art. 19 de la LSSI-CE- y, por otro, las referidas comunicaciones comerciales deben ser claramente identificables, indicando la persona física y jurídica en nombre da la cual se realizan, e incluyendo la palabra "Publicidad" o la abreviatura "publi", en virtud de la modificación operada por la 56/2007, de 28 de diciembre, de Medidas de Impulso de la Sociedad de la Información ${ }^{101}$ (LISI), cuando se haga a través de correo electrónico u otro medio de comunicación electrónica ${ }^{102}$ -art. 20 LSSI-CE-. Considerando que la abreviatura informa inequívocamente del contenido publicitario, y no se menoscaban los derechos de los

\footnotetext{
100 Illescas Ortiz, Rafael (2004). "Oferta, perfección y prueba del contrato electrónico". Estudios de Derecho Judicial, $\mathrm{N}^{\circ}$ 50, pp. 213-242.

101 BOE núm. 312 de 29 de diciembre de 2007.

102 Si la intención que el legislador español persigue, con la mención de la palabra "publicidad" o "publi", es que su destinatario no tenga, si así lo considera, que leer las comunicaciones comerciales completas o, en el mejor de los casos, proceder a la apertura del correo, no se comprende la alusión de que dicha palabra deba constar al comienzo del mensaje. Hubiera sido más oportuno que se estableciera la obligación de que la expresión que comentamos constara en el asunto del mensaje. De esta forma, se evitarían, además, conflictos de interpretación que podrían polemizar sobre si la obligación legal se cumple o no cuando la palabra publicidad o su abreviatura "publi" se incluye con caracteres realmente pequeños al comienzo del cuerpo del mensaje.
} 
destinatarios, se facilita la comunicación a través de dispositivos con pantalla en formato reducido como terminales de telefonía móvil.

La redacción que, en la actualidad, presenta el art. 21 de la LSSI-CE procede de la reforma operada por la Ley española 32/2003, de 3 de noviembre, General de Telecomunicaciones ${ }^{103}$-LGT-. La regulación de las comunicaciones comerciales se asienta en un principio general: la exigencia del consentimiento del destinatario ${ }^{104}$, si bien existen excepciones vinculadas, en todo caso, al cumplimiento de ciertos presupuestos que aseguran que se trate de un consentimiento extraordinario y que, incluso, en tal caso, se garantice la posibilidad de oposición del destinatario mediante un procedimiento sencillo y gratuito y la transparencia del mensaje ${ }^{105}$.

Debemos, en este sentido, advertir que la parte del art. 21 que analizamos podría contradecir el art. 15 del Real Decreto 1720/2007, de 21 de diciembre, por el que se aprueba el Reglamento de desarrollo de la Ley Orgánica española 15/1999, de 13 de diciembre, de Protección de Datos de carácter Personal ${ }^{106}$-Reglamento de la LOPD-. Este último -no olvidemos que de carácter reglamentario- preceptúa que "si el responsable del tratamiento solicitase el consentimiento del afectado durante el proceso de formación de un contrato para finalidades que no guarden relación directa con el mantenimiento, desarrollo o control de la relación contractual, deberá permitir al afectado que manifieste su negativa al tratamiento o comunicación de datos". Algunos autores ${ }^{107}$ consideran que este precepto constituye una manifestación del sistema opt out.

Nótese, en todo caso, que el carácter del precepto que analizamos -art. 21 de la LSSI-CE- es más restrictivo que la Ley Orgánica española 15/1999, de 13 de diciembre, de Protección de Datos de carácter Personal $^{108}$ (LOPD), pues no podrán remitirse comunicaciones comerciales sin el previo consentimiento del afectado, ni siquiera en el supuesto de que los datos provengan de fuentes accesibles al público ${ }^{109}$, lo que es diferente

103 Publicado en BOE núm. 264 de 4 de noviembre de 2003.

104 A tenor del art. 3.h) de la LOPD, el consentimiento del interesado es "toda manifestación de voluntad, libre, inequivoca, especifica e informada, mediante la que el interesado consienta el tratamiento de datos personales que le conciernen". Asimismo, debe advertirse que el consentimiento, además de previo, específico e inequívoco, debe ser informado. Y esta información habrá de ser plena y exacta en relación tanto al tipo de tratamiento como a su finalidad, con advertencia de la facultad de denegar o retirar el consentimiento. Esta información constituye un requisito necesario para dar validez a la manifestación de voluntad del afectado.

105 Aparicio Vaquero, Juan Pablo (2005). "Régimen jurídico de las comunicaciones comerciales realizadas a través del correo electrónico". La Ley, N 4, pp. 1476-1489.

106 Publicado en BOE núm. 17 de 19 de enero de 2008.

107 Paniza Fullana, Antonia (2008). "Tratamientos para actividades de publicidad y prospección comercial”. En Martínez Martínez, Ricard (Coord.): Protección de datos. Comentarios al Reglamento de Desarrollo de la LOPD. Valencia: Tirant lo Blanch, p. 256.

108 Publicado en BOE núm. 298 de 14 de diciembre de 1999.

109 Panilla Fullana (2008) 255. 
a lo que acontece en otros países (caso, por ejemplo, de Chile ${ }^{110}$ ). A pesar de cuanto manifestamos, existen resoluciones judiciales que se pronuncian en sentido contrario como la Sentencia de la Audiencia Nacional de España de 3 de octubre de 2007 (RJCA 2007/675 ${ }^{111}$ ). Esta última revoca una sanción de la Agencia Española de Protección de Datos ${ }^{112}$-AEPD_ por haber enviado publicidad a través de correo electrónico ${ }^{113}$ sin obtener previamente el consentimiento del titular del mismo. La Audiencia Nacional, no obstante, considera que el correo electrónico fue obtenido de una fuente accesible al público ${ }^{114} \mathrm{y}$, en consecuencia, entiende aplicable la excepción prevista en el art. 6.2 de la LOPD.

Procede detenerse, si bien brevemente, en que la gratuidad no se extiende a los posibles costes de la transmisión de esta negativa -al tratamiento de los datos personales con fines promocionales-, que, en todo caso, tendría que soportarlos el inicial receptor. Esta cuestión que comentamos se omite en la LSSI-CE, pero sí se trata en el considerando 41 de la Directiva comunitaria 2002/58/CE, aunque, posteriormente, no se concreta, con más detalle, en su articulado. Se trata de una materia, asimismo, abordada en el Informe 25/2007 de la AEPD sobre el consentimiento para la remisión de comunicaciones comerciales, alcanzándose la conclusión de que la revocación del consentimiento por el afectado en ningún caso puede generar coste alguno.

110 En tal Estado, los spammers, con relativa habitualidad, determinan que el mensaje se envía a tenor de los arts. 2 (letra "i") y 4 de la Ley 19.628 de derecho a la privacidad. De hecho, de estos últimos preceptos se infiere que la regla general en Chile son los datos personales que provienen de fuentes públicas -que se definen en términos amplios y ambiguos- y, por consiguiente, los mismos pueden tratarse sin el consentimiento de sus titulares. Como puede advertirse, se trata de normas totalmente originarias de la legislación chilena, que no están contempladas, en los mismos términos, en otras legislaciones de Derecho comparado -como Francia y España-.

111 La referencia de la citada resolución judicial procede de Westlaw Aranzadi (España).

112 Como bien determina Rallo Lombarte, Artemi (2009). "La protección de datos en España”. Anuario de la Facultad de Derecho de la Universidad de Alcalá, Vol. 2, p. 18, la AEPD es la autoridad de control independiente que vela por el cumplimiento sobre la normativa de protección de datos, garantizando y tutelando el derecho fundamental a la protección de datos de carácter personal. En Chile, sin embargo, no existe organismo equivalente. No impera organismo de control, en materia de protección de datos, si bien hay una autoridad registral con funciones limitadas a los organismos públicos que son responsables de bases de datos. Sobre las alternativas que, durante la tramitación de la ley de protección de datos, se discutieron nos remitimos a Cumplido Cereceda, Francisco (1997). "Análisis del anteproyecto de ley sobre protección de datos personales elaborado por el Ministerio de Justicia (1990-1994)”. Ius et Praxis, No 1, pp. 201-208.

113 La dirección concreta de correo electrónico, dado que contiene información sobre su titular, o, en la medida en que permita identificar al mismo, ha de ser considerada como dato de carácter personal y su tratamiento sometido a la LOPD. En consecuencia, con carácter general, no será posible su utilización o cesión si el interesado no ha dado su consentimiento para ello.

114 En este sentido, se recomienda la lectura del informe 0105/2010 de la Agencia Espańola de Protección de Datos que aborda una cuestión vinculada con cuanto comentamos. 
La modificación realizada por la LGT sobre el art. 21 de la LSSI-CE, que antes comentábamos, a pesar de su ambigüedad, ha sido acogida con agrado, ya que, respetando el derecho a la protección de datos del destinatario de la comunicación, tiene en consideración que el normal desarrollo de las relaciones contractuales implica el ofrecimiento de nuevos servicios y productos.

Ha de insistirse en que el consentimiento para el envío de comunicaciones comerciales electrónicas debe ser, en cualquier caso, expreso ${ }^{115}$. No es válido el que se otorga de forma tácita. Son ilícitas las peticiones genéricas para autorizar la recepción de publicidad en abstracto, pues, como hemos anticipado, el consentimiento debe ser expreso ${ }^{116}$. Cabe indicar que el destinatario de las comunicaciones comerciales electrónicas podrá haber prestado su consentimiento en virtud de diferentes prácticas comerciales. Así, por ejemplo, pueden citarse las casillas electrónicas que constan marcadas por defecto, la solicitud de confirmación del registro operado en un determinado sitio Web, etc. Está proliferando la creación de listas de inclusión voluntaria -también denominadas listas de preferencias-. A través de las mismas, se suelen remitir, de forma automática, mensajes de correos electrónicos -sin contenido publicitario alguno- para que el destinatario, mediante la pulsación del enlace electrónico, confirme el alta. Consideramos que este método sí que acreditaría el consentimiento expreso por parte de su titular. Lo que no debe entenderse, en modo alguno, como consentimiento tácito, para la remisión de comunicaciones comerciales, es el hecho de haber recibido, a su vez, spam. En efecto, la recepción de comunicaciones comerciales no solicitadas de terceros, no autoriza al destinatario de las mismas a la remisión, por su parte, de mensajes publicitarios (igualmente no solicitados) a dichos remitentes ${ }^{117}$. En otros términos, la recepción de spam no permite -pues no existe consentimiento- a su destinatario a actuar en el mismo sentido -remitiendo, igualmente, spam al emisor inicial-. Por decirlo en términos coloquiales,

115 El hecho de que la LSSI-CE imponga la necesidad de que el consentimiento deba ser expreso aumenta, de manera considerable, las restricciones para el remitente de la comunicación comercial y, por ende, las garantías para el destinatario. Asimismo, introduce un plus de exigencia respecto a la LOPD, pues esta norma únicamente establece la obligación de que el consentimiento deba ser inequívoco. Sobre este particular, Guillén Catalán (2009) 116.

116 Sobre extremo, recomendamos la consulta de López Jiménez, David (2009). "El valor del silencio en el ámbito del comercio electrónico: comunicaciones, productos y servicios no solicitados". Revista Jurídica del Notariado, N71, pp. 114-120.

117 Este fue precisamente el supuesto de hecho objeto de examen en el procedimiento sancionador de la AEPD 00426/2012. En base al mismo, se castigó a la entidad demandada, como consecuencia de una infracción del art. 21.1 de la LSSI-CE, tipificada como leve en el artículo 38.4.d) de la LSSI, al abono de una multa de 2.000 euros. Todo ello de acuerdo con lo previsto en los artículos 39. 1.c) y 40 de la citada LSSI-CE. 
el que recibe spam no tiene autorización -ya que no se ha efectuado consentimiento por la otra parte- para contestar con más spam ${ }^{118}$.

El último párrafo del artículo 21.2 de la LSSI-CE, en la redacción operada por el Real Decreto-Ley español 13/2012, de 30 de marzo, a efectos de oposición de la remisión de mensajes publicitarios, especifica, como apuntamos, que "cuando las comunicaciones hubieran sido remitidas por correo electrónico, dicho medio deberá consistir necesariamente en la inclusión de una dirección electrónica válida ${ }^{119}$ donde pueda ejercitarse este derecho, quedando probibido el envio de comunicaciones que no incluyan dicha dirección". En cuanto a tal precepto, debemos determinar que el anteproyecto de ley únicamente incluía la primera parte del precepto, es decir, "cuando las comunicaciones comerciales hubieran sido remitidas por correo electrónico el medio para oponerse al tratamiento de datos deberá consistir necesariamente en la inclusión de una dirección electrónica válida en la que se pueda ejercitar ese derecho por parte del destinatario de la comunicación". Ahora bien, el artículo 13.4 de la Directiva europea 2002/58/CE (Directiva sobre la privacidad), redactado por el art. 2 de la Directiva 2009/136/ $\mathrm{CE}^{120}$, señala, de manera expresa, que se prohibirán las comunicaciones comerciales en las que no se incluya esa dirección electrónica válida. Con buen criterio, el Consejo de Estado español -supremo órgano consultivo del Gobierno de tal Estado-, con la finalidad de incorporar la Directiva con la mayor fidelidad posible, propuso añadir, al final de la redacción proyectada del art. 21.1, la oración "quedando prohibido el envío de las comunicaciones que no incluyan dicha dirección”. La misma observación efectuó en relación con el párrafo segundo del artículo 22.1 de la LSSICE. Ambas reflexiones, fueron incorporadas a la versión definitiva de la modificación. Se trata, en suma, de permitir la posibilidad de revocar el consentimiento prestado a la recepción de comunicaciones comerciales cuando estas se hayan mandado por correo electrónico.

Una vez que hemos visto el régimen jurídico imperante relativo al spam, a tenor del Derecho español -sin perjuicio de las apreciaciones de Derecho comparado efectuadas-, cabe referirse a una situación que incluso podría llegar a calificarse de anecdótica. Debe advertirse que, como es,

118 El envío recíproco o mutuo de correos comerciales únicamente resultaría legítimo en el caso de que dichos mensajes (publicitarios) respondieran bien a una solicitud o autorización, previa y expresa, de los mismos entre ambas partes bien estas fueran clientes entre sí. Como hemos determinado, en este tipo de envíos comerciales, a través de medios de comunicación electrónica, no cabe el consentimiento implícito o tácito para recibir tales mensajes.

119 En cuanto al significado de la expresión dirección electrónica válida, a tenor de la Directiva 2009/136/CE, podría ser interpretado como una dirección de correo electrónico o un enlace directo o link para cursar la baja, que, a través de un proceso automático, garantice la satisfacción de la pretensión del usuario que no desea recibir más comunicaciones comerciales.

120 Diario Oficial n ${ }^{\circ}$ L 337 de 18 de diciembre de 2009. 
en cierta medida, obvio, cuando se reciben comunicaciones comerciales no solicitadas, es posible que el receptor de las mismas, conocedor de sus derechos, denuncie el hecho en cuestión ante la AEPD y que este último organismo proceda en consecuencia. Lo que quizás podría resultar llamativo es que esta última -la AEPD- sea el destinatario ${ }^{121}$.

El régimen de las comunicaciones comerciales de la LSSI-CE se entiende sin perjuicio de las normas dictadas por las Comunidades Autónomas de España con competencias exclusivas sobre consumo, comercio electrónico o publicidad -art. 20.3 de la LSSI-CE en su redacción operada por la Ley española 56/2007, de 28 de diciembre, de Medidas de Impulso de la Sociedad de la Información ${ }^{122}$. . Aplicando analógicamente la regla de preferencia contenida en el párrafo 2 del art. 94 del Real Decreto Legislativo español 1/2007, de 16 de noviembre, por el que se aprueba el Texto Refundido de la Ley General para Defensa de los Consumidores y Usuarios y otras Leyes complementarias ${ }^{123}$-TRLGDCU-, las eventuales contradicciones entre la normativa de consumo y la legislación específica sobre servicios de la sociedad de la información y comercio electrónico se resolverán a favor de esta última ${ }^{124}$.

121 Aunque el medio, en virtud del que se remitió spam, no fue propiamente correo electrónico, está parcialmente vinculado, ya que tuvo lugar a través de fax. En efecto, centrándonos en el supuesto de hecho, a pesar de lo paradójico de la situación, la propia AEPD recibió, en reiteradas ocasiones - hasta un total de nueve-, diversos mensajes no solicitados en los que la misma era destinataria de servicios de recobros de morosos. Si bien la AEPD intentó ponerse en contacto con la empresa emisora, sus pretensiones fueron, en cualquier caso, en vano. En base a todo ello, se publicó, en el Boletín Oficial del Estado Español, acuerdo de inicio de procedimiento de carácter sancionador. En virtud del mismo, la empresa emisora de este tipo de comunicaciones comerciales no solicitadas fue castigada por una infracción del art. 38.3.h) de la LGT, tipificada como grave en el art. 38.3.c) de la LSSI. Se le impuso la condena de abonar una multa pecuniaria que ascendió a un total de 30.001 euros de acuerdo con lo previsto en los arts. 39.1.b), 40 de la LSSI-CE, y art. 53.z) de la LGT. Publicado en BOE núm. 312 de 29 de diciembre de 2007.

123 Publicado en BOE núm. 287 de 30 de noviembre de 2007.

124 Miranda Serrano, Luis María (2011). "Contratos celebrados a distancia”. En Rebollo Puig, Manuel e Izquierdo Carrasco, Manuel (Dirs.): La defensa de los consumidores y usuarios. Comentario sistemático del Texto Refundido aprobado por el Real Decreto Legislativo 1/2007. Madrid: Iustel, p. 1464, añade que en el supuesto de que la LSSI-CE entre en conflicto con el TRLGDCU, por regular los mismos extremos -pero de forma distinta-, deberá acogerse la solución de la LSSI-CE. Del mismo modo, cuando no existan discrepancias legales, ambas normativas deberán aplicarse, de manera complementaria o concurrente, ya que la contratación electrónica representa una modalidad de contratación a distancia y, por ello, ha de someterse a su normativa reguladora. Como se indicaba en el Dictamen del Consejo de Estado (de Espańa) sobre el Proyecto de Real Decreto Legislativo por el que se aprueba el Texto Refundido de la Ley General para la defensa de los consumidores, de 20 de julio de 2006, era necesario recoger la regla de la preferencia de la normativa específica sobre la contratación electrónica para que el TRLGDCU no supusiera una modificación sustancial del régimen vigente en materia de comercio electrónico que hubiera supuesto un exceso en el uso de la delegación legislativa. 
Estamos ante una materia en la que, dada sobre todo su transnacionalidad $^{125}$, resulta especialmente visible la limitación de la normativa legal. Por ello, entendemos que lo más aconsejable sería la aprobación de herramientas derivadas de la autorregulación que complementen las disposiciones aprobadas por el legislador ${ }^{126}$. Todo ello sería posible en virtud del principio de la autonomía de la voluntad.

\section{3) El ACOSO COMO PRÁCTICA COMERCIAL DESLEAL EN LA MATERIA}

Ahora bien, si se remitiera insistentemente spam, concurriendo la oposición del destinatario, tal práctica podría ser reputada desleal. En efecto, a tenor del art. 29.2 de la Ley española 3/1991, de 10 de enero, de Competencia Desleal ${ }^{127}$ (LCD), "se reputa desleal realizar propuestas no deseadas y reiteradas por teléfono, fax, correo electrónico u otros medios de comunicación a distancia, salvo en las circunstancias y en la medida en que esté justificado legalmente para hacer cumplir una obligación contractual'.

Mientras la LSSI-CE, como vimos, se apoya en un sistema de opt-in en el que el destinatario debe consentir, con carácter previo, la recepción de mensajes publicitarios remitidos por medios electrónicos de comunicación a distancia, la LCD se basa en un sistema opt-out por el que únicamente se reputan desleales los mensajes comerciales enviados por medios de comunicación a distancia a destinatarios que, con carácter precedente, se hayan opuesto al envío. Asimismo, en la LCD el juicio de deslealtad se condiciona a la persistencia en la remisión de la publicidad no deseada.

Sin embargo, ha de advertirse que la norma no detalla cuántas propuestas han de realizarse para que puedan considerarse reiteradas. Tal posición parece correcta, dado que se hace depender de las circunstancias concurrentes en el supuesto concreto. Dado que la práctica que comentamos se considera un supuesto de acoso, podría estimarse de aplicación el art. 8.2 de la LCD, según el cual "para determinar si una conducta hace uso del acoso, la coacción o la influencia indebida se tendrán en cuenta: a. El momento y el lugar en que se produce, su naturaleza o su persistencia; b. El empleo de un lenguaje o un comportamiento amenazador o insultante; c. La explotación por parte del empresario o profesional de cualquier infortunio o

\footnotetext{
125 Dado el carácter transfronterizo del spam, se han puesto en marcha varias iniciativas de cooperación con fines de represión de tal técnica. Por ello, la Comisión Europea creó una Red de contacto de las autoridades responsables en materia de spam, denominada Contact Network of Spam Enforcement Authorities, que tiene por finalidad mantener reuniones periódicas, favorecer el intercambio de las mejores prácticas en esta materia y facilitar la colaboración para la aplicación transfronteriza de la ley, además de elaborar un procedimiento de cooperación para permitir la tramitación transfronteriza de las denuncias.

126 Schmidhuber, Martin (2004). Verhalenskodices im nationalem und genzuberschreitenden electronischen Gescafsverkehr. Fráncfort: Peter Lang GmbH, pp. 151-165.

127 Publicado en BOE de 11 de enero de 1991.
} 
circunstancia especificos lo suficientemente graves como para mermar la capacidad de discernimiento del destinatario, de los que aquel tenga conocimiento, para influir en su decisión con respecto al bien o servicio; $d$. Cualesquiera obstáculos no contractuales onerosos o desproporcionados impuestos por el empresario o profesional cuando la otra parte desee ejercitar derechos legales o contractuales, incluida cualquier forma de poner fin al contrato o de cambiar de bien o servicio o de suministrador; e. La comunicación de que se va a realizar cualquier acción que, legalmente, no pueda ejercerse".

En cualquier caso, como dispone el mencionado art. 29 de la LCD, la ausencia de los presupuestos necesarios para la declaración de deslealtad, no será óbice para que un mensaje comercial remitido electrónicamente sea considerado ilícito si, en nuestro caso, vulnera la LSSI-CE o la LOPD.

\section{4) LOS FICHEROS DE EXCLUSIÓN VOLUNTARIA O LISTAS ROBINSON}

Una de las herramientas más sugerentes para poner coto a la remisión de comunicaciones comerciales electrónicas es en virtud de los denominados ficheros de exclusión voluntaria o también llamados listas Robinson ${ }^{128}$. Si bien nos ocuparemos, con cierto detalle, del régimen jurídico imperante en España, tales herramientas han sido creadas en diversos países europeos como, entre otros, fueron los casos de Francia ${ }^{129}$ y Bélgica $^{130}$.

\section{1) DELIMITACIÓN CONCEPTUAL}

Respecto a las opciones que el consumidor tiene al alcance, para ejercer su derecho de oposición, se encuentra la posibilidad de inscribirse en los ficheros de exclusión voluntaria que pueden ser de carácter general o sectorial $^{131}$. Antes de entrar en materia, debe apuntarse que ni la LOPD

128 Se trata de una lista que parece obtener su denominación del náufrago Robinson Crusoe. De hecho, parece representar una alusión al deseo de estar aislado de la publicidad, del mismo modo que este aventurero lo estuvo del mundo en una isla desierta.

129 La Federación de Empresas de Venta a Distancia -FEVAD- fue la primera en poner en marcha una lista de exclusión voluntaria de oposición a la prospección por correo electrónico.

130 La Asociación Belga de Marketing Directo -ABMD- también estableció, de forma pionera, una lista de oposición a la que se sumaron las listas de oposición propias de cada uno de los miembros de la citada asociación.

131 En Chile, desde agosto de 2013, con buen criterio, el SERNAC creó la aplicación virtual "No Molestar", en la que los usuarios interesados pueden introducir sus datos con la finalidad de solicitar su eliminación de las listas de envíos masivos publicitarios y/o promocionales que existen en las empresas y, de esta manera, no recibir más mensajes comerciales no deseados. Una vez que los usuarios han realizado tal actuación, el SERNAC 
ni su Reglamento de desarrollo definen, de forma expresa, lo que debe entenderse por estos últimos (los ficheros de exclusión voluntaria o lista Robinson). En cualquier caso, podríamos afirmar que son ficheros (de exclusión) en los que puede inscribirse cualquier persona que no desee recibir comunicaciones comerciales ${ }^{132}$.

Entre las opciones disponibles, en la actualidad, en España, destaca la denominada Lista Robinson ${ }^{133}$ cuya gestión está a cargo de la Federación de Comercio Electrónico y Marketing Directo ${ }^{134}$ (FECEMD). Aunque funciona desde comienzos de los noventa, representa, como decimos, un fichero de exclusión publicitaria que, como se deduce del Reglamento de la LOPD, evita la recepción de publicidad no deseada ${ }^{135}$.

No debe, en absoluto, dejarse de lado el coste que para los anunciantes supone la consulta de tales ficheros de exclusión. Así, por lo que se refiere a la lista Robinson, las empresas no adheridas a FECEMD deberán abonar ciertas cuantías -que para la suscripción anual es de 550 euros más IVA-. En todo caso, aunque la iniciativa parece loable, no debe, insistimos, perderse de vista las cantidades que los anunciantes tendrán que soportar.

Debe, en todo caso, repararse en que nos encontramos ante un sugerente instrumento complementario que en modo alguno sustituye los derechos que el legislador español reconoce, con carácter mínimo, al potencial consumidor y/o usuario.

notificará, una vez al mes, a las empresas, de acuerdo a los antecedentes ingresados por el interesado, su deseo de no recibir más comunicaciones publicitarias. Si la empresa emisora no actúa en consecuencia y, por consiguiente, infringe la normativa legal, la institución -el SERNAC- tiene la facultad de multar e incluso, si procede, iniciar acciones legales contra el infractor. Dejando a un lado esta loable iniciativa, el propio destinatario de las comunicaciones comerciales, al amparo del art. 12.4 de la Ley 19.628, podrá reclamar la eliminación, o bloqueo de los datos.

132 El Reglamento del Fichero de la Lista Robinson de FECEMD, en su art. 1, define esta sugerente figura -fichero de lista Robinson- como "fichero que contiene la información facilitada directamente por los propios interesados o por sus representantes legales, definiéndose como un fichero común de exclusión publicitaria al amparo de lo dispuesto en el artículo 49 del RLOPD”.

133 La misma es accesible a través del sitio Web: www.listarobinson.es.

134 Tal entidad cuenta tanto con el Comité de Protección del Tratamiento Automatizado de los Datos de carácter personal como con un Código Ético de Protección de Datos Personales del sector del Marketing Directo, en virtud del cual el Comité interviene. Si este último considera que una empresa adherida a FECEMD ha vulnerado la lista Robinson, podrá recomendar una acción disciplinaria y, si procede, la suspensión como miembro adherido al servicio. El Comité podría, además, publicitar convenientemente la sanción, así como emprender acciones legales en caso de que de la mala práctica se deriven comportamientos ilícitos que repercutan sobre la credibilidad de esta actividad de marketing directo.

135 Respecto a tal figura, Davara Rodríguez, Miguel Ángel (2009). "Sobre las denominadas listas Robinson”. El Consultor de los Ayuntamientos y de los Juzgados, N 15, pp. 2-8. 


\section{2) A PROPÓSITO DE SU POSIBLE CONSIDERACIÓN COMO MANIFESTACIÓN DE LA AUTORREGULACIÓN DEL SECTOR}

Tal actuación representa un nuevo ejemplo de autorregulación de las empresas que operan en el sector del marketing directo ${ }^{136}$. Antes de ocuparnos sobre lo que ello supone, en nuestro campo concreto de estudio, esbozaremos unas breves pinceladas relativas a la autodisciplina. Esta puede definirse como el respeto voluntario de unas normas de conducta cuyo cumplimiento se ha fijado, con carácter previo, como objetivo. Constituye la posibilidad de que un círculo concreto de personas afines, por el ejercicio de la misma actividad, someten esta última a un elenco de reglas que ellas mismas, de forma facultativa, se autoimponen. Esta última constituye un fenómeno que no es, en absoluto, reciente. Cualquier organización, cualquier sujeto, de una u otra forma, se autorregulan. Tal hecho resulta jurídicamente relevante cuando esa autorregulación rebasa el marco privado, doméstico, de origen, proyectando sus efectos sobre un radio de acción notablemente más amplio -en ciertas ocasiones, será supranacional-, alcanzando, a su vez, a los poderes públicos. Durante el siglo XX a las normas derivadas de la autorregulación, como regla general, se les atribuyó una eficacia limitada en cuanto a su capacidad para regular comportamientos sociales. En la actualidad, el escenario que planteamos ha cambiado notablemente y, con ello, el recurso a herramientas de autodisciplina, como instrumentos reguladores de ámbitos relevantes del Derecho privado -dentro del que se encuentra el vinculado, directa o indirectamente, con el comercio electrónico, lo que, naturalmente, engloba la remisión de comunicaciones comerciales electrónicas-, ha crecido de manera muy significativa. Esta relevancia aumenta, si cabe, aún más si tenemos en consideración el proceso de globalización en el que todavía estamos inmersos, provocado, en parte, por la influencia económica, política y social que Internet ejerce.

Que la autorregulación se desenvuelve entre la sociedad y el Estado, entre lo privado y lo público, es evidente y, simultáneamente, consustancial al concepto que se maneja, centrado en la autodisciplina que surge en la órbita privada, pero que alcanza relevancia pública. De hecho, el gran hallazgo de la autorregulación es que no implica una fractura entre el Estado y la sociedad, ya que no supone la separación completa entre ambos. De hecho, los poderes públicos -generalmente el legislador español en esta materia opera, como anticipamos, a impulsos del comunitario- persiguen fomentar diversas manifestaciones de la autorregulación con el ob-

136 La lista Robinson, gestionada por FECEMD, cuando inicialmente se ideó, se encontraba regulada por un código de conducta cuya fecha de redacción data de 1992. 
jetivo de que las mismas coadyuven a la consecución de loables objetivos públicos.

Puede, en este sentido, disponerse que, como decimos, la autorregulación se vincula a la articulación de nuevas estrategias reguladoras fomentadas por los poderes públicos. En realidad, se trata de mejorar la eficacia de la regulación estatal ${ }^{137}$.

Debe reconocerse, al hilo de cuanto comentamos, la posibilidad de que la consecución de los intereses generales se atribuya también a organizaciones y sujetos de origen y naturaleza privada. Asimismo, surge la necesidad de considerar a determinados instrumentos privados elaborados por aquellos como una importante herramienta que puede ser utilizada por la propia Administración para el cumplimiento de sus fines. A este respecto, las listas Robinson, gracias a la autorregulación del sector que, en este complejo escenario, interactúa, complementan lo dispuesto por el legislador español. De hecho, como hemos adelantado, permiten que los consumidores y/o usuarios manifiesten su expresa oposición al hecho de recibir determinadas comunicaciones comerciales, entre las que se encuentran aquellas que se remiten por medios digitales.

De hecho, el recurso a la autorregulación es especialmente apropiado en aquellos ámbitos en los que la experiencia ha puesto de manifiesto la existencia de algún déficit en la protección legal al consumidor, de la que los códigos de conducta son una manifestación ${ }^{138}$. La elaboración y puesta en práctica de los ficheros de exclusión voluntaria se erige en una interesante técnica privada de tutela que permite complementar a los demás instrumentos públicos normativos, redundando, en consecuencia, en un mayor grado de amparo para los consumidores y usuarios.

Con buen criterio, las empresas del marketing directo, en España, han puesto en práctica tal medida, ya que son conscientes del efecto negativo que en los potenciales consumidores y/o usuarios tienen las comu-

137 No obstante, debe tratarse de verdadera autorregulación, en el sentido de que la asunción de las normas voluntarias que se inserten en tal fenómeno devengan en verdaderos compromisos exigibles. No debe reputarse tal las meras recomendaciones o sugerencias. En este último sentido, podríamos destacar la autodisciplina fomentada en Chile, en 2002, por la Subsecretaria de Telecomunicaciones (SUBTEL) y por la entidad gremial que integra a los proveedores de Internet-API-, que no gozó de eficacia, precisamente, por tal motivo.

138 En el caso del Reino Unido, debe precisarse que el recurso a los mismos, en el ámbito de la protección de datos de carácter personal, fue propuesto por el Informe Lindop (Lindop Report) de 1984, dadas sus ventajas inherentes, durante los estudios preliminares a la primera normativa que se aprobó en dicho espacio territorial. Existen algunos ejemplos que han adquirido alcance comunitario. En este sentido, el código de conducta europeo relativo al uso de los datos de carácter personal, en el sector de la venta directa, de la Federación de Asociaciones Europeas de Venta Directa (FEDMA). En el escenario latinoamericano también podríamos destacar algunos ejemplos al respecto. En el caso concreto de Chile, podemos referirnos, entre otros muchos, al código de buenas prácticas de la Cámara de Comercio de Santiago. 
nicaciones no deseadas. Estos últimos pueden, de forma gratuita, darse de alta en tales ficheros. Sin embargo, en el caso de los menores de 14 ańos será necesario que lo realicen sus padres o tutores, mientras que en el supuesto de los incapacitados deberá operarse por sus representantes legales. A tal efecto, se tendrá que completar un formulario en el que se detallará por qué canales -teléfono, SMS, correo electrónico e incluso por vía postal- no se desean recibir comunicaciones comerciales personalizadas.

El art. 49.4 del Reglamento de la LOPD impone a los anunciantes el deber de consultar los ficheros de exclusión para no remitir publicidad a las personas que han manifestado su oposición, inscribiéndose, a tal efecto, en las mismas. Este dispone que "quienes pretendan efectuar un tratamiento relacionado con actividades de publicidad o prospección comercial deberán previamente consultar los ficheros comunes que pudieran afectar a su actuación, a fin de evitar que sean objeto de tratamiento los datos de los afectados que hubieran manifestado su oposición o negativa a ese tratamiento". Debe precisarse que el deber de consultar previamente los ficheros de exclusión también resulta exigible en el supuesto de que los datos personales figuren en fuentes accesibles al público.

A nuestro modo de ver, teniendo en cuenta la redacción del citado precepto, podrían suscitarse ciertas dudas sobre si las listas de exclusión resultan obligatorias para todos los anunciantes o únicamente para las entidades adheridas al sistema que voluntariamente las ponga en práctica. Nos posicionamos a favor de la última opción, ya que, entre otras cuestiones, parece la más respetuosa con el fenómeno de la autorregulación ${ }^{139}$. No olvidemos que, aunque no parece deseable, en la práctica, podrán crearse numerosos ficheros de exclusión a cargo de entidades privadas -además de la ideada por FECEMD-, por lo que su consulta podría llegar a ser especialmente gravosa -desde distintas perspectivas (económica, temporal, etc.)- para los anunciantes ${ }^{140}$.

139 El establecimiento de servicios de ficheros de exclusión de necesaria observancia, al modo de los National Do not Call Registry (Registro Nacional de no llamar) norteamericano y canadiense, parece no resultar posible en el ordenamiento jurídico español. Existen otras experiencias dignas de valoración. Así, por ejemplo, México cuenta con el Registro Público para Evitar Publicidad administrado por la Procuraduría Federal del Consumidor. En Brasil existe el Registro para Bloqueo de Recibir Llamadas de Telemercadeo-Cadastro para Bloqueio do Recebimento de Ligaçóes de Telemarketing-, en el seno de los programas de protección de consumidor.

140 La consulta de la lista Robinson, a cargo de la FECEMD, debe considerarse posible únicamente en virtud del principio de la autonomía de la voluntad. En otros términos, no existe norma, legal o reglamentaria, alguna que establezca este deber para los prestadores de servicios ya que se obligan ellos mismos al suscribir, en base al principio de la autonomía privada, el contrato de prestación de servicios de uso de la lista. 
Aunque nos encontramos ante una figura diversa a los códigos tipo $^{141}$-que es otra manifestación de la autorregulación-, comparte algunos caracteres comunes con los mismos. En efecto, en primer término, ambos son de carácter voluntario y, además, deberán inscribirse en la AEPD. Y, en segundo lugar, a nuestro entender, su vulneración comportará sanciones solo para los adheridos ${ }^{142}$. Estas últimas podrán imponerse tanto por la $\mathrm{AEPD}^{143}$ como por la entidad que esté a cargo del fichero de exclusión que, en el caso de la Lista Robinson actualmente vigente, habrán, en su caso, de aplicarse por FECEMD en aplicación del Reglamento regulador.

Respecto a las sanciones que, en su caso, procedan, por parte de la AEPD, debe señalarse que, a tenor de los artículos 30.4 de la LOPD, y 49.4 del Reglamento de desarrollo de la LOPD -todo ello en relación con lo dispuesto en el art. 6 de la LOPD-, la entidad que, existiendo oposición expresa del afectado, en virtud de la lista Robinson, remitiera comunicaciones comerciales, estaría tratando de los datos de carácter personal sin el consentimiento inequívoco del interesado.

En consecuencia, una vez acreditado el tratamiento de los datos por la AEPD, y negado por el interesado, dicho consentimiento inequívoco, corresponde a la parte imputada que efectúa el tratamiento justificar que contaba con el repetido consentimiento que sirviera de cobertura al tratamiento realizado. Asimismo, la Sentencia de la Audiencia Nacional de España de 11 de mayo de 2001 dispone que "... quien gestiona la base, debe estar en condiciones de acreditar el consentimiento del afectado, siendo carga de la prueba del mismo su justificación, y la entidad recurrente en ningún momento ha realizado esfuerzo probatorio tendente a la acreditación del consentimiento de las personas en las que se basa la sanción".

De acuerdo con el artículo 44.3.c) de la LOPD, se considera infracción grave "tratar los datos de carácter personal o usarlos posteriormente con

141 Los códigos tipo son objeto de atención por parte del art. 32 de la LOPD, por el Título VII -arts. 71 a 78- así como por el capítulo VI del Título IX del Reglamento de desarrollo de la LOPD -arts. 146 a 152- donde se determinan los requisitos formales y de fondo que los mismos han de reunir. La adhesión a tales figuras pone de manifiesto el compromiso, por parte de la entidad que asume su respeto, del cumplimiento del articulado contenido en el mismo. Este último incluirá la propia normativa legal -que ajustará a ciertos escenariosmás, en numerosas ocasiones, determinadas previsiones más garantistas que las reconocidas, con carácter mínimo, por el legislador.

142 Para, precisamente, identificar a las empresas usuarias de la lista Robinson, la propia FECEMD ha ideado un sello de calidad, de uso facultativo. Una de las sanciones que cabe frente al incumplimiento del fichero de exclusión es la retirada del sello ideado al efecto.

143 Sobre este particular, se recomienda, por un lado, la lectura del Procedimiento Sancionador 00654/2010 contra Telefónica Móviles de Espańa a iniciativa de un particular. La mencionada entidad fue sancionada con una multa de 3.000 euros. Y, por otro, en sentido similar, el procedimiento sancionador $00168 / 2011$, en la que se condenó a la demandada al abono de una multa de 5.000 euros. 
conculcación de los principios y garantías establecidos en la presente Ley". Por consiguiente, se está describiendo una conducta -el tratamiento automatizado de datos personales o su uso posterior- que precisa, para configurar el tipo, que la misma haya vulnerado los principios que establece la LOPD. El principio del consentimiento se configura como principio básico en materia de protección de datos ${ }^{144}$. En el caso que analizamos, tiene cabida legal en el art. 30.4 de la LOPD cuando permite al titular de los datos "revocar u oponerse" a un determinado tratamiento, lo que pone de relieve el poder de disposición y control sobre los datos personales.

Siguiendo con el supuesto que planteamos, si el prestador de servicios adherido a la lista Robinson incumpliera con los compromisos que tal adhesión representa, $y$, a este respecto, remitiera comunicaciones comerciales a un determinado destinatario que, con carácter previo, hubiera manifestado su oposición, se estaría vulnerando el citado principio del consentimiento. De concurrir tal supuesto, los datos del denunciante serían tratados en los ficheros del prestador de servicios de que se trata sin su consentimiento. Esto es, sin observancia de lo dispuesto en el art. 30.4 de la LOPD. Todo ello motivaría la imposición de las sanciones previas a las que nos hemos referido.

\section{CONCLUSIONES}

Al igual que acontece en el mundo tradicional, también en el espacio virtual se remiten numerosos mensajes comerciales a personas que no han manifestado su consentimiento. Los Estados que decidan combatir el spam deberán, previamente, decidir si optan por un sistema opt-in (consentimiento expreso o inclusión voluntaria) u opt-out (oposición explícita o exclusión voluntaria). El primero -opt-in-, vigente sobre todo en Europa, únicamente permite el envío de comunicaciones comerciales a quienes hubieran manifestado su consentimiento previo y específico. El sistema opt-out, vigente en Estados Unidos y en otros países como Chile, consiente realizar comunicaciones comerciales, salvo que el destinatario manifieste su rechazo.

La inclusión voluntaria representa la expresión del consentimiento previo. Tal alternativa parece ser la más proclive al comercio electrónico. En efecto, en lugar de finalizar una relación comercial, en virtud de las listas de exclusión voluntarias o listas Robinson -que no son sino la manifestación del derecho de oposición-, en el caso de las listas de inclusión,

144 Con carácter general, dicho principio tiene reflejo en el art. 6 de la LOPD, si bien su desarrollo y efectos se plasman durante todo el texto legal y la normativa de desarrollo, por razón de la materia. 
el empresario sugiere al consumidor y/o usuario continuar con la relación comercial. De alguna manera, está en marcha el marketing consentido o autorizado. La inclusión voluntaria, por sus caracteres inherentes, presenta un elenco nada desdeńable de prerrogativas. Así, entre otros aspectos, fomenta la contratación de un bien y/o servicio, ya que, al poner de relieve sus expectativas, pone de manifiesto información con cierto valor añadido.

Para poner freno a las comunicaciones comerciales no solicitadas, se han elaborado los denominados ficheros de exclusión voluntaria o Listas Robinson. Estos últimos constituyen una sugerente manifestación de la autodisciplina del sector, fomentada, dicho sea de paso, por el legislador de España a impulsos del europeo. En base a los mismos, los consumidores y/o usuarios pueden manifestar, haciendo uso del principio de la autonomía privada, su oposición a la remisión de comunicaciones comerciales, a través de ciertos canales, respecto a bienes y servicios de determinadas empresas. La inscripción en esta modalidad de listas podrá realizarse tanto antes como después de haber recibido mensajes comerciales no solicitados, sin perjuicio de que lo más habitual será este último supuesto. Se trata de una herramienta complementaria y no sustitutiva, en modo alguno, de la normativa legal imperante.

Aunque hemos visto tales figuras a tenor del Derecho español, cabe determinar que podrían representar un buen punto de referencia para ciertos países de América Latina como es el caso de Chile. En esta línea, parecen apuntar algunas iniciativas puestas recientemente en marcha por parte del SERNAC que ha ideado la aplicación virtual "No Molestar", en la que los usuarios interesados pueden introducir sus datos con la finalidad de solicitar su eliminación de las listas de envíos masivos publicitarios y/o promocionales que existen en las empresas y, de esta manera, no recibir más mensajes comerciales no deseados.

\section{BibLIOGRAFÍA}

- Acosta Estévez, José (1990). Perfiles de la Ley General de Publicidad. Barcelona: Promociones y Publicaciones Universitarias, $138 \mathrm{pp}$.

- Alpa, Guido (1986). Diritto privato dei consumi. Bolonia: Il Mulino, 411 pp.

- Suárez Villegas, Juan Carlos y Pérez Chica, María Ángeles (2002). La publicidad al desnudo. Sevilla: Editorial Mad, 99 pp.

- Alonso Espinosa, Francisco José (2009). "Artículo 2". En LÁzaro SÁnchez, Emilio (Coord.): Comentario a la Ley General de Publicidad. Navarra: Thomson Reuters y Civitas, pp. 22-34. 
- Álvarez Rubio, Julio (2008). "Hacia un nuevo concepto legal de comunicación comercial". En Tomillo Urbina, Jorge Luis (Dir.) y Álvarez Rubio, Julio (Coord.): El futuro de la protección jurídica de los consumidores. Actas del I Congreso Euroamericano de Protección Jurídica de los Consumidores. Navarra: Thomsom Civitas y Cátedra Euroamericana de Protección Jurídica de los Consumidores, pp. 115-128.

- Aparicio Vaquero, Juan Pablo (2005). "Régimen jurídico de las comunicaciones comerciales realizadas a través del correo electrónico”. La Ley, № 4, pp. 1476-1489.

- Arean Lalín, Manuel (1982). "En torno a la función publicitaria de la marca". Actas de Derecho Industrial, $\mathrm{N}^{\circ} 8$, pp. 57-84.

- Arias Pou, María (2006). Manual Práctico de Comercio Electrónico. Madrid: La Ley, 1061 pp.

- Banda Vergara, Alfonso (2000). "Manejo de datos personales. Un límite al derecho a la vida privada". Revista de Derecho (Valdivia), No 11, pp. 55-70.

- Bassat, Luis (2003). El libro rojo de la publicidad. Barcelona: Planeta, 318 pp.

- Beater, Axel (2000). "Zum Verhältnis von europäischen und nationnalen Wettbewerbsrecht (Überlegungen am beispiel des schutzes vor irreführender werbung und des verbraucherbegriffs)". GRUR Int., No 1, pp. 960-981.

- Bodewig, Theo (2000). "Electronischer Geschäftsverkehr und Unlauterer Wettbewerb". GRUR Int., No 27, pp. 415-490.

- Brandeis, Samuel y Warren, Louis (1890). "The right to privacy", Harvard Law Review, No 5, pp. 193-220.

- Burgos y Luz de León, Daniel (2001). Comercio electrónico, publicidad y marketing en Internet. Madrid: McGraw-Hill, 215 p.

- Carbonnier Jean (1965). Derecho Civil, Tomo 1. Barcelona: Bosch, $931 \mathrm{pp}$.

- Cerda Silva, Alberto (2006). "Algunas consideraciones sobre los códigos de conducta en la protección de los datos personales". Revista Chilena de Derecho Informático, No 8, pp. 121-132.

- Cerdá Silva, Alberto (2006). "Mecanismos de control en la protección de datos en Europa". Ius et Praxis, $\mathrm{N}^{\circ} 36$, pp. 221-251.

- Cerdá Silva, Alberto (2011). "El "nivel adecuado de protección" para las transferencias internacionales de datos personales desde la Unión Europea”. Revista de Derecho de la Pontificia Universidad Católica de Valparaiso, N ${ }^{\circ} 36$, pp. 327-356.

- Cooley, Thomas (1888). A Treatise on the Law of Torts or the Wrongs which arise independent of contract. Chicago: Callaghan, 899 pp. 
- Corral Talciani, Hernán (2000). "Configuración Jurídica del derecho a la privacidad II: concepto y delimitación". Revista Chilena de Derecho, $\mathrm{N}^{\circ} 2$, pp. 331-355.

- Cumplido Cereceda, Francisco (1997). "Análisis del anteproyecto de ley sobre protección de datos personales elaborado por el Ministerio de Justicia (1990-1994)". Ius et Praxis, No 1, pp. 201-208.

- Davara Rodríguez, Miguel Ángel (2009). "Acerca del spam". El Consultor de los Ayuntamientos y de los Juzgados, $\mathrm{N}^{\circ} 13$, pp. 1-9.

- Davara Rodríguez, Miguel Ângel (2009). "Sobre las denominadas listas Robinson". El Consultor de los Ayuntamientos y de los Juzgados, $\mathrm{N}^{\circ} 15$, pp. 2-8.

- De Asís Roig, Agustín (2004). "Comentarios a la Disposición Final Primera". En García de Enterría, Eduardo y De la Cuadra-Salcedo, Tomás (Coords.): Comentarios a la Ley General de Telecomunicaciones, Ley 32/2003, de 3 de noviembre. Navarra: Thomson Aranzadi, pp. 1205-1218.

- De la Maza Gazmuri, I. (2002). "El correo en los tiempos de Internet". Anuario de Filosofía Jurídica y Social, No 20, pp. 261-321.

- De la Maza Gazmuri, I. (2002). "Privacidad y comercio electrónico". En De la Maza Gazmuri, I. (Coord.): Derecho y Tecnologías de la Información. Santiago: Escuela de Derecho Universidad Diego Portales, pp. 265-279.

- De la Maza Gazmuri, Iñigo (2010). "El suministro de información como técnica de protección de los consumidores: los deberes precontractuales de información". Revista de Derecho de la Universidad Católica del Norte, $\mathrm{N}^{\circ} 2$, pp. 21-52.

- De la Maza Gazmuri, Ińigo (2010). Los límites del deber precontractual de información. Navarra: Civitas y Thomson Reuters, 413 pp.

- De la Maza Gazmuri, Ińigo (2010). “Tipicidad y atipicidad de los deberes precontractuales de información". Revista de Derecho de la Pontificia Universidad Católica de Valparaíso, № 34, pp. 75-99.

- De la Maza Gazmuri, Iñigo (2011). "La distribución del riesgo y la buena fe. A propósito del error, el dolo y los deberes precontractuales de información". Revista de Derecho de la Pontificia Universidad Católica de Valparaiso, No 37, pp. 115-135.

- De Miguel Asensio, Pedro Alberto (2005). Régimen jurídico de la publicidad transfronteriza. Madrid: Iustel, $452 \mathrm{p}$.

- De Pablos Heredero, Carmen (2004). Informática y comunicaciones en la empresa. Madrid: Esic, 316 pp.

- Del Peso Navarro, Emilio (2003). Servicios de la Sociedad de la Información. Madrid: Díaz de Santos, 387 pp. 
- Desantes guanter, José María (1980). "El marco jurídico de la publicidad en el contexto de la información". En Primeras Jornadas de Derecho de la Publicidad. Madrid: Instituto Nacional de Publicidad, pp. 12-39.

- Dolnicar, Sara y JordaAn, Yolanda (2007). "A market oriented approach to responsibly managing information privacy concerns in direct marketing". Journal of Advertising, Vol. 36, $\mathrm{N}^{\circ}$ 2, pp. 123-149.

- Durán Alba, Juan Fernando (2006). "El derecho a la libertad informática (según el art. 18.4 CE) como límite al correo electrónico no solicitado”. En Carrasco Durán, Manuel PÉrez Royo, Javier Urías Martínez, Joaquín Pablo y Terol Becerra, Manuel (Coords.): Derecho constitucional para el siglo XXI: actas del VIII Congreso Iberoamericano de Derecho Constitucional. Navarra: Aranzadi, pp. 1539-1569.

- Espinosa Calabuig, Rosario (2001). La publicidad transfronteriza. Valencia: Tirant lo Blanch, 237 p.

- Fernández Novoa, Carlos (1968). "La interpretación jurídica de las expresiones publicitarias". Revista de Derecho Mercantil, N 107, pp. 14-43.

- Fernández Novoa, Carlos (1989). "La interpretación jurídica de las expresiones publicitarias. Introducción al estudio de los principios generales de la publicidad". En Estudios de Derecho de la Publicidad (Homenaxe da Facultade de Dereito ó Autor Dr. Carlos Fernández Novoa). Santiago de Compostela: Universidade de Santiago de Compostela, pp. 57-86.

- Fernando Magarzo, María del Rosario (2001). "Concepto de publicidad y publicidad engañosa en Internet". Revista de la Contratación Electrónica, $\mathrm{N}^{\circ} 21$, pp. 3-66.

- Font Galán, Juan Ignacio (1990). "El tratamiento jurídico de la publicidad en la Ley General para la Defensa de los Consumidores y Usuarios". En Curso sobre el nuevo Derecho del consumidor. Madrid: Ministerio de Sanidad y Consumo, Instituto Nacional de Consumo, pp. 55-101.

- García Guerrero, José Luis (1996). "Publicidad y libertad de expresión en el ordenamiento constitucional español”. Derecho Privado y Constitución, N ${ }^{\circ}$ 10, pp. 117-146.

- Gauthronet, Serge y Drouard, Etienne (2001). Communications commerciales Non-Sollicitées et Protection des Données. Bruselas: Internal Market DG-Contract, $153 \mathrm{pp}$.

- Ghidini, Gustavo (1968). Introduzione allo studio della pubblicitá comerciale. Milán: Giuffrè, 250 pp.

- Ghidini, Gustavo (2001). "Funzione distintiva e valore pubblicitario del marchio. Profili e critica di un evolucione”. En 
GHIDIni, Gustavo: Profili evolutivi del Diritto Industriale. Milán: Giuffré, pp. 123-153.

- Gondra Romero, José María (1996). "Teoría general de signos de empresa”. En Iglesias Prada, Juan Luis (Coord.): Estudios jurídicos en homenaje al Profesor Aurelio Menéndez. Madrid: Civitas, pp. 829-868.

- Guillén Catalán, Raquel (2005). Spam y comunicaciones comerciales no solicitadas. Navarra: Thomson Aranzadi, 218 pp.

- Guillén Catalán, Raquel (2009). "Las comunicaciones comerciales en el marco de la contratación electrónica”. En Orduña Moreno, Javier y Aguilera Anegón, Gonzalo (Dirs.), y Plaza Penadés, Javier y Balluguera Gómez, Carlos (Coords.): Comercio, administración y registro electrónicos. Navarra: Thomson Reuters, pp. 69-138.

- Guillén Catalán, Raquel (2010). El régimen jurídico de la oferta contractual dirigida a consumidores. Madrid: Colegio de Registradores de la Propiedad y Mercantiles de España, 220 p.

- HaAn, Sarah (2000). "The persuasion route of the Law: advertising and legal persuasion". Columbia Law Review, Vol. 100, N 5, pp. 1281-1326.

- Hafner, Katie (2003). "A Change of Habits To Elude Spam's Pull”. The New York Times, 23 de octubre, pp. 1-3.

- Hall, Mark (1997). "Four models on how advertising works". Commercial Communications. The Journal of Advertising and Marketing Policy and Practice in the European Community, $\mathrm{N}^{\circ}$ 9, pp. 6-34.

- Illescas Ortiz, Rafael (2003). "Comunicaciones comerciales y oferta contractual electrónicas: la propuesta de contrato entre la prohibición y las incertezas". Revista de la Contratación Electrónica, $\mathrm{N}^{\circ} 40$, pp. 5-23.

- Illescas Ortiz, Rafael (2004). "Oferta, perfección y prueba del contrato electrónico". Estudios de Derecho Judicial, N 50, pp. 215242.

- Jijena Leiva, Renato (2010). "Spam y Derecho. Consideraciones críticas sobre la regulación de las comunicaciones comerciales por correo electrónico en las leyes 19628 y 19946”. Memorias del XIV Congreso Iberoamericano de Derecho e Informática. Monterrey: Instituto de Investigaciones Jurídicas de la UNAM, pp. 432-447.

- Kes, Yusuf (2011). "Current approaches in e-advertisement". International Journal of Business and Social Science, Vol. 2, N 21, pp. 124-137.

- LeE, Monle (2004). "Attitudes toward direct marketing, privacy, environment and trust: Taiwan vs. U.S.". International Journal of Consumer Marketing, Vol. 14, N 1, pp. 1-18. 
- Lombarte, Artemi (2009). "La protección de datos en España". Anuario de la Facultad de Derecho de la Universidad de Alcalá, Vol. 2, pp. 15-30.

- López Jiménez, David (2009). "El valor del silencio en el ámbito del comercio electrónico: comunicaciones, productos y servicios no solicitados". Revista Jurídica del Notariado, N 71, pp. 105-126.

- López Jiménez, David y Martínez López, Francisco José (2010). "Nuevas coordenadas en el ámbito de la Web 2.0: el caso de la publicidad comportamental". Revista de Estudios Económicos y Empresariales de la Universidad de Extremadura, N ${ }^{\circ} 22$, pp. 101-134.

- López Jiménez, David (2012). "El servicio de geolocalización con fines comerciales como novedosa manifestación de la Web 2.0". Revista Veritas, No 9, pp. 90-98.

- López Jiménez, David y Castillo Girón, Víctor Manuel (2012). "En torno al conflicto entre nombres de dominio y otros signos distintivos de las empresas: la política uniforme de solución de controversias". Revista de Estudios Económicos y Empresariales, No 24, pp. 183-217.

- López Jiménez, David (2013). La publicidad en Internet. Regulación y autorregulación. Navarra: Thomson Reuters, $312 \mathrm{pp}$.

- Martín García, María del Lirio (2002). La publicidad. Su incidencia en la contratación. Madrid: Dykinson, 328 p.

- Miquel Rodríguez, Jorge (2001). "Problemática jurídica de la publicidad en Internet". En Botana García, Gema Alejandra (Coord.): Comercio Electrónico y Protección de los Consumidores. Madrid: La Ley, pp. 245-274.

- Miranda Serrano, Luis María (2011). "Contratos celebrados a distancia”. En Rebollo Puig, Manuel e Izquierdo Carrasco, Manuel (Dirs.): La defensa de los consumidores y usuarios. Comentario sistemático del Texto Refundido aprobado por el Real Decreto Legislativo 1/2007. Madrid: Iustel, pp. 1443-1562.

- Muñiz Espada, Esther (2003). "Algunas consideraciones sobre la nueva Ley de Servicios de la Sociedad de la Información y de Comercio Electrónico". En Cabanillas Sánchez, Antonio (Coord.): Estudios Jurídicos en homenaje al profesor Luis Diez-Picazo. Madrid: Thomson Civitas, pp. 2677-2694.

- Nigra, Amedeo (2001). La publicitá e suoi contratti tipici. Roma: Maggioli, $374 \mathrm{p}$.

- Novoa Monreal, Eduardo (1977). Derecho a la vida privada y libertad de información. Santiago: Siglo XXI Editores, 223 pp.

- Otero Lastres, José Manuel (1977). "La protección de los consumidores contra la publicidad ilícita". Actas de Derecho Industrial y Derecho de Autor, Tomo 4, pp. 113-128. 
- Paniza Fullana, Antonia (2004). "Comunicaciones comerciales no solicitadas y marketing directo: el sistema opt out como excepción (correo electrónico y mensajes SMS con fines publicitarios)". En Ramos, Benjamín y Ribagorda, Arturo (Dirs.): Avances en criptografía y seguridad de la información. Madrid: Díaz de Santos, pp. 437-446.

- Paniza Fullana, Antonia (2008). "Algunas reflexiones sobre la normativa aplicable a los contratos a distancia celebrados con consumidores: problemas y contradicciones". En Cotino Hueso, Lorenzo (Coord.): Consumidores y usuarios ante las nuevas tecnologías. Valencia: Tirant lo Blanch, pp. 69-84.

- Paniza Fullana, Antonia (2008). "Tratamientos para actividades de publicidad y prospección comercial”. En Martínez Martínez, Ricard (Coord.): Protección de datos. Comentarios al Reglamento de Desarrollo de la LOPD. Valencia: Tirant lo Blanch, pp. 245-263.

- Pardo López, María Magnolia (2009). “Artículo 3”. En Lázaro SÁnchez, Emilio (Coord.): Comentario a la Ley General de Publicidad. Navarra: Thomson Reuters y Civitas, pp. 57-68.

- Patiño Alvés, Beatriz (2002). "Comunicaciones comerciales por vía electrónica”. Revista de la Contratación Electrónica, N³0, pp. 111 146.

- Patiño Alvés, Beatriz (2002). "Las comunicaciones comerciales por vía electrónica”. En III Jornadas sobre Derecho del Comercio Electrónico organizadas por la Universidad Carlos III de Madrid. Madrid: Universidad Carlos III, pp. 2-15.

- Peinado Gracia, Juan Ignacio (1998). “Comparación y denigración publicitarias de la imagen de empresas indirectamente aludidas (reflexiones con ocasión de la sentencia del Tribunal Supremo de 24 de febrero de 1997)". Revista de Derecho Mercantil, N²30, pp. 1601-1652.

- Peña González, Carlos, (1999). "Notas sobre las relaciones entre privacidad y autonomía". Revista Jurídica de la Universidad de Palermo, No 19 , pp. 69-76.

- PÉrez, Alberto (1980). "El concepto jurídico de la publicidad". En Primeras Jornadas de Derecho de la Publicidad. Madrid: Instituto Nacional de Publicidad, pp. 78-101.

- Pino Abad, Manuel (1991). La disciplina juridica en la actividad publicitaria en la Ley de publicidad de 1988. Madrid: Ministerio de Sanidad y Consumo, 178 p.

- Rivero González, María Dolores (2003). “Régimen jurídico de la publicidad en Internet y las comunicaciones comerciales no solicitadas por correo electrónico". Revista de Derecho Mercantil, ${ }^{\circ}$ 250, pp. 1587-1614. 
- Rodríguez Casal, Carlos y Loza Correa, María (2002). "Protección de la privacidad. Aproximación al opt-in/opt-out". Revista de la Contratación Electrónica, No 23, pp. 3-18.

- Rodríguez de las Heras Ballel, Teresa (2006). "La formación del contrato en el entorno electrónico y los procedimientos electrónicos de contratación". En Calvo Caravaca, Alfonso Luis y Carrascosa GonZÁlez, Javier (Dirs.): Estudios sobre Contratación Internacional. Madrid: Colex, pp. 535-572.

- Romero Giménez, Manuel (1995). "Publicidad engañosa”. En Propiedad Industrial y Competencia Desleal. Madrid: Consejo General del Poder Judicial, pp. 163-189.

- Rothchild, John (1999). "Protecting the Digital Consumer: The Limits of Cyberspace Utopianism". Indiana Law Journal, No 3, pp. 893-989.

- Ruiz Miguel, Carlos (2001). "Protección de datos personales y comercio electrónico". En Gómez Segade, José Antonio (Dir.): Comercio electrónico en Internet. Madrid: Marcial Pons, pp. 397-416.

- Sampol Pucurrull, Miguel (2005). "Administración Electrónica". En De Fuentes Bardají, Joaquín (Dir.) y Pereña Pinedo, Ignacio (Coord.): Manual de Derecho Administrativo Sancionador. Navarra: Thomson Aranzadi y Ministerio de Justicia, pp. 1753-1776.

- Sánchez del Castillo, Vilma (2007). La publicidad en Internet. Régimen Jurídico de las comunicaciones electrónicas. Madrid: La Ley, $442 \mathrm{p}$.

- Santaella López, Manuel (1989). El nuevo Derecho de la publicidad. Madrid: Civitas, 236 pp.

- Schmidhuber, Martin (2004). Verhalenskodices im nationalem und genzuberschreitenden electronischen Gescafsverkehr. Franfurt: Peter Lang $\mathrm{GmbH}, 351 \mathrm{pp}$.

- Schryen, Guido (2007). "Anti-spam legislation: An analysis of laws and their effectiveness". Information \& Communications Technology Law, Vol. 16, $\mathrm{N}^{\circ} 1$, pp. 17-32.

- Spang, Kurt (2005). Persuasión. Fundamentos de retórica. Pamplona: Eunsa, 294 pp.

- Stazi, Andrea (2004). La pubblicità commerciale on line. Milán: Giuffrè Editore, 192 pp.

- Tato Plaza, Anxo (1994). "La explotación publicitaria de los sentimientos y el derecho de la competencia desleal: el caso "Benetton". Derecho de los Negocios, No 44, pp. 13-17.

- Tato Plaza, Anxo (2001). "Aspectos jurídicos de la publicidad y de las comunicaciones comerciales en Internet". En Gómez Segade, José Antonio (Dir.) y Fernández-Albor Baltar, Ángel y Tato Plaza, Anxo (Coords.): Comercio electrónico en Internet. Madrid: Marcial Pons, pp. 187-223. 
- Tato Plaza, Anxo (2004). "La publicidad en Internet". En González Delgado, José Ángel (Coord.): Responsa iurisperitorum digesta. Salamanca: Ediciones de la Universidad de Salamanca, pp. 89-104.

- Tato Plaza, Anxo (2004). "La publicidad en Internet”. En Moro Almaraz, María Jesús (Dir.); y Aparicio Vaquero, Juan Pablo y Batuecas Caletrío, Alfredo (Coords.): Autores, consumidores y comercio electrónico. Madrid: Colex y Caja Duero, pp. 141-156.

- Tejedor Muñoz, Lourdes (2010). "Consideraciones en torno a la publicidad confusionista a la luz de Ley 29/2009, de 30 de diciembre, por la que se modifica el régimen legal de la competencia desleal y de la publicidad para la mejora de la protección de los consumidores y usuarios". Revista Critica de Derecho Inmobiliario, ${ }^{\circ}$ 721, pp. 2433-2447.

- Tejedor Muñoz, Lourdes (2010). "La publicidad engañosa, comparativa y prácticas comerciales desleales". En DíAz-Ambrona Bajardí, María Dolores (Dir.): Derecho Civil de la Unión Europea, 4a edición. Madrid: Colex, pp. 265-290.

- Ugarte Cataldo, José Luis (2011). "Privacidad, trabajo y derechos fundamentales". Estudios Constitucionales, N ${ }^{\circ}$ 1, pp. 13-36.

- Vega Vega, José Antonio (2005). Contratos electrónicos y protección de los consumidores. Madrid: Reus, $495 \mathrm{pp}$.

- Vidal Portabales, José Ignacio (2010). "Algunas notas sobre formación y perfección de los contratos electrónicos en la Ley 34/2002, de 11 de julio (LSSI Y CE)”. En Gómez Segade, José Antonio y García Vidal, Ángel (Coords.): El Derecho mercantil en el umbral del siglo XXI. Libro homenaje al Prof. Dr. Carlos FernándezNovoa en su octogésimo cumpleaños. Madrid-Barcelona: Marcial Pons, pp. 663-677.

- Vilasau, Mónica (2006). "La Directiva 2006/24/CE sobre conservación de datos del tráfico en las comunicaciones electrónicas: seguridad v. privacidad". Revista de los Estudios de Derecho y Ciencia Politica de la UOC, $\mathrm{N}^{\circ} 3$, pp. 1-15. 